\title{
Metal-Organic-Frameworks: Low Temperature Gas Sensing and Air Quality Monitoring
}

\author{
Xiaohu Chen ${ }^{1}\left(\mathbb{D}\right.$, Reza Behboodian ${ }^{2}$, Darren Bagnall ${ }^{3}$, Mahdiar Taheri ${ }^{4}\left(\mathbb{D}\right.$ and Noushin Nasiri ${ }^{1, *} \mathbb{(}$ \\ 1 NanoTech Laboratory, School of Engineering, Faculty of Science and Engineering, Macquarie University, \\ Sydney, NSW 2109, Australia; jayden.chen@hdr.mq.edu.au \\ 2 School of Engineering, Central Queensland University, Sydney Campus, Sydney NSW 2000, Australia; \\ behboodianreza@gmail.com \\ 3 School of Engineering, Faculty of Science and Engineering, Macquarie University, \\ Sydney, NSW 2109, Australia; darren.bagnall@mq.edu.au \\ 4 Research School of Engineering, The Australian National University, Canberra, ACT 2601, Australia; \\ mahdiar.taheri@anu.edu.au \\ * Correspondence: noushin.nasiri@mq.edu.au
}

Citation: Chen, X.; Behboodian, R.; Bagnall, D.; Taheri, M.; Nasiri, N. Metal-Organic-Frameworks: Low Temperature Gas Sensing and Air Quality Monitoring. Chemosensors 2021, 9, 316. https://doi.org/ $10.3390 /$ chemosensors 9110316

Academic Editors: Andrea Gaiardo, Barbara Fabbri and Vincenzo Guidi

Received: 5 October 2021

Accepted: 2 November 2021

Published: 8 November 2021

Publisher's Note: MDPI stays neutral with regard to jurisdictional claims in published maps and institutional affiliations.

Copyright: (c) 2021 by the authors. Licensee MDPI, Basel, Switzerland. This article is an open access article distributed under the terms and conditions of the Creative Commons Attribution (CC BY) license (https:/ / creativecommons.org/licenses/by/ $4.0 /)$.

\begin{abstract}
As an emerging class of hybrid nanoporous materials, metal-organic frameworks (MOFs) have attracted significant attention as promising multifunctional building blocks for the development of highly sensitive and selective gas sensors due to their unique properties, such as large surface area, highly diversified structures, functionalizable sites and specific adsorption affinities. Here, we provide a review of recent advances in the design and fabrication of MOF nanomaterials for the lowtemperature detection of different gases for air quality and environmental monitoring applications. The impact of key structural parameters including surface morphologies, metal nodes, organic linkers and functional groups on the sensing performance of state-of-the-art sensing technologies are discussed. This review is concluded by summarising achievements and current challenges, providing a future perspective for the development of the next generation of MOF-based nanostructured materials for low-temperature detection of gas molecules in real-world environments.
\end{abstract}

Keywords: metal-organic frameworks; hybrid nanomaterials; gas sensing; selectivity; sensitivity

\section{Introduction}

In recent decades, the rapid growth of urban populations has resulted in new public health concerns and environmental pollution [1,2], and the fast monitoring of air- and waterborne contaminants using effective sensors has grown considerably in importance $[1,3]$. An effective sensor should interact with the target analyte selectively with high sensitivity and short response time [2,4-6]. In addition, the sensor should be cost-effective and demonstrate high reusability and reproducibility [2,7]. Sensors can be utilized to detect pollutants/analytes in aqueous (such as heavy metals, toxic organic compounds, and antibiotics) and gaseous form (such as volatile organic compounds, toxic gases, and greenhouse gases) $[2,6,8,9]$. The latter has a wide range of applications in food quality processes, industrial gases detection, and disease diagnosis, as well as indoor air-quality monitoring [8,10-12].

Several gas-sensing techniques have been developed including optical, capacitive, chemoresistive, and magnetic sensors [8,13-33]. In optical sensing, material optical properties change upon adsorption of the target analyte onto the surface producing an optical signal such as a change in visible colour, refractive index, luminescence intensity, etc. [27,32] Capacitive-based sensors are an attractive class of sensors, in which capacitance changes due to the change in the dielectric permittivity upon adsorbing the gas/vapour molecules are detected [28-30]. In chemoresistive detectors, electrical conductivity changes as a result of a reaction between the target gas and oxygen molecules adsorbed on the surface 
of the sensing material $[4,21,33]$. Generally, chemoresistive-based gas sensors provide a superior sensing response at room temperature compared to optical-based gas sensors. However, their slow response dynamic at low/room operating temperature and their lack of selectivity towards target gases hinder their real-world application [4-6].

In magnetic gas sensors, the magnetic properties of the sensing material are changed upon exposure to the target gas molecules; the change can be measured by, for example, application of the Hall effect, magnetization, spin orientation, ferromagnetic resonance, the magneto-optical Kerr effect, or the magnetostatic wave oscillation effect [8,13$15,17-26,31,34,35]$. Sensing materials for gas detection can be classified into metal oxides [16,36,37], conductive and non-conductive polymers [38-41], carbon-based materials (e.g., graphene, carbon nanotubes, etc.) [42-46], noble metal-based structures [47-50], ionic liquids [51-53], metal-organic frameworks [8,54-56], and their composites [57-59]. Among these material groups, metal oxide-based sensors have been investigated extensively due to their strong and rapid response, low limit of detection (LOD), high reproducibility, simple and portable design, and low fabrication cost [60-62]. In recent years, the development of nanostructures and nanocomposites of metal oxide sensors has further improved device sensing characteristics. Despite these advantages and improvements, high operating temperature and inadequate gas selectivity have hindered substantial growth into new markets $[61,63,64]$. Polymers have been utilized in gas sensors as a sensing agent (mainly in a functionalized state) or immobilizing component to overcome some of these challenges $[38,65]$. Although significant progress in polymer sensors has been achieved over the last 20 years, these sensors encounter difficulties, including complex sensing mechanisms, poor selectivity towards target gases, a slow response dynamic, and significant matrix aging [22,38].

MOFs, a class of porous coordination polymers (PCPs), are crystalline frameworks with open porosity and are composed of metal nodes and organic linkers [66,67]. Over the last two decades, numerous compounds have been synthesised by changing the metal ions and organic ligands to produce materials with exceptional properties, including large surface area (surface areas more than $1,000 \mathrm{~m}^{2} \mathrm{~g}^{-1}$ ), adjustable pore size, and tunable functional groups $[8,21,68]$. The manifold approaches for MOF synthesis, including the most versatile and widely used solvothermal methods, and recently realised green approaches, such as solvent-free mechanochemical routes [69-72], are making the process of preparing high-quality MOF-based materials easier and more environmentally friendly. Hence, MOFs have attracted much attention for numerous potential applications such as gas absorption/storage, gas separation, gas sensing, catalysis, solar energy conversion, energy storage, and biomedical technology/drug delivery [71,73-77].

Among the unique properties of MOFs, the reversible and selective adsorption of guest molecules onto their large surface areas is of great importance for sensing applications [2,54]. In fact, a high concentration of target gases inside a highly porous structure boosts the sensitivity of the sensor and the control over functional groups and pore sizes of the framework enhances the selectivity of the detection process [54]. Furthermore, in contrast to carbon-based and metal oxide-based sensors, which require high working temperature, MOF-based sensors have shown promising performances at low/room temperatures, resulting in significant reductions in power consumption, ease of manufacture and broadened application areas [78-81]. The variation in MOFs' physical and chemical properties following the adsorption of intended gas molecules has been exploited for the effective monitoring of environmental pollutants, indoor air quality, medical diagnosis and other areas of application $[8,11,29,82,83]$.

Here, we present recent advances in the design and fabrication of MOF-based nanosensors for low concentration detection of different gases including nitrogen dioxide $\left(\mathrm{NO}_{2}\right)$, hydrogen sulfide $\left(\mathrm{H}_{2} \mathrm{~S}\right)$, sulfur dioxide $\left(\mathrm{SO}_{2}\right)$, carbon dioxide $\left(\mathrm{CO}_{2}\right)$ and ammonia $\left(\mathrm{NH}_{3}\right)$, for air quality and environmental monitoring applications. We critically assess and compare state-of-the-art MOF-based nanostructured technologies that are leading the way in developing sensitive and selective gas sensors with low operating temperatures 
(Table 1). We focus on the impact of nanostructured morphologies, metal nodes, organic linkers, and functional groups, as well as gas-sensing mechanisms on the performance of state-of-the-art sensing technologies. We conclude with a review of the rapidly emerging trends and promising strategies that can enhance functionality and enable the production of the next generation of highly sensitive and selective MOF-based gas sensors for the low-temperature detection of gas molecules.

Table 1. Key features of MOF-based gas sensors for air quality monitoring.

\begin{tabular}{|c|c|c|c|c|c|c|c|}
\hline Gas & Materials & Sensor Type & $\begin{array}{l}\text { Working } \\
\text { Cond. }\end{array}$ & $\begin{array}{c}\text { Con./LOD } \\
(\mathrm{ppm})\end{array}$ & Response \#\# & $\mathrm{T}_{\text {res }} / \mathrm{T}_{\text {rec }} \$ \$$ & Ref. \\
\hline \multirow{13}{*}{$\mathrm{NO}_{2}$} & $\mathrm{~Tb}-\mathrm{MOF}$ & Optical & $\begin{array}{l}\text { RT, UV (350 } \\
\text { nm) }\end{array}$ & $5 / 1.8$ & $0.55(\Delta \mathrm{PL} / \mathrm{PL})$ * & $\begin{array}{c}<2 \min ^{\mathrm{a}} / \sim 2 \\
\min \end{array}$ & [84] \\
\hline & Eu-MOF & Optical & $\begin{array}{l}\text { RT, UV ( } 350 \\
\text { nm) }\end{array}$ & $5 / 2.2$ & $0.11(\Delta \mathrm{PL} / \mathrm{PL})$ * & $90 \mathrm{~s}^{\mathrm{b}} /-$ & [84] \\
\hline & MOF-A & Optical & RT & $100 \% /-$ & $\begin{array}{l}\text { Red to yellow } \\
\text { during exposure }\end{array}$ & 1 & [85] \\
\hline & MOF-A & Chemoresistive & $\mathrm{RT}, 0.5 \mathrm{~V}$ & $100 \% /-$ & $\begin{array}{c}\text { Resistance } \\
\text { decreased from } \\
0.57 \mathrm{~T} \Omega \\
\text { to } 0.25 \mathrm{M} \Omega \text { then } \\
\text { further down to } \\
\quad 9.1 \mathrm{~K} \Omega\end{array}$ & $2 \min / 42 \mathrm{~s}^{\mathrm{c}}$ & [85] \\
\hline & Y-DOBDC & Optical & RT, UV/Vis & 1 & $\begin{array}{c}\text { Yellow to } \\
\text { brown-orange } \\
\text { (@Vis } \\
\text { illumination) }\end{array}$ & $\backslash$ & [32] \\
\hline & Ni-MOF-74 & Capacitive & $\begin{array}{c}50^{\circ} \mathrm{C}, 10 \\
\mathrm{mHz}-1 \mathrm{MHz}\end{array}$ & $5 /<0.5$ & $725\left(\mathrm{R}_{1} / \mathrm{R}_{2}\right)^{\mathrm{d}}$ & 1 & [86] \\
\hline & $\mathrm{In}_{2} \mathrm{O}_{3} / \mathrm{ZIF}-8$ & Chemoresistive & $140^{\circ} \mathrm{C}$ & $1 / 0.01$ & $16.4\left(\mathrm{R}_{\mathrm{g}} / \mathrm{R}_{\mathrm{a}}\right)$ & $80 \mathrm{~s} / 133 \mathrm{~s}$ & [87] \\
\hline & $\mathrm{Cu}_{3}(\mathrm{HHTP})_{2} / \mathrm{Fe}_{2} \mathrm{O}_{3}$ & Chemoresistive & RT, Blue light & $5 / 0.011$ & $63.5 \%\left(\Delta \mathrm{R} / \mathrm{R}_{0}\right)$ & 1 & [88] \\
\hline & $\mathrm{Pd} @ \mathrm{Cu}_{3}(\mathrm{HHTP})_{2}$ & Chemoresistive & $\mathrm{RT}, 5 \% \mathrm{RH}$ & $5 /-$ & $\begin{array}{l}-62.11 \% \\
\left(\Delta R / R_{0}\right)\end{array}$ & $13.8 \mathrm{~min} /-$ & [89] \\
\hline & 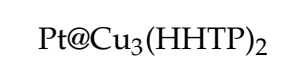 & Chemoresistive & $\mathrm{RT}, 5 \% \mathrm{RH}$ & $5 /-$ & $\begin{array}{l}-57.38 \% \\
\left(\Delta R / R_{0}\right)\end{array}$ & $14 \mathrm{~min} /-$ & [89] \\
\hline & $\mathrm{Pt} @ \mathrm{Cu}_{3}(\mathrm{HHTP})_{2}$ & Chemoresistive & RT & $3 / 0.1$ & $89.9 \%\left(\Delta \mathrm{R} / \mathrm{R}_{0}\right)$ & $8.2 \mathrm{~min} /-$ & [90] \\
\hline & $\mathrm{Cu}_{3}(\mathrm{HHTP})_{2}$ & Chemoresistive & RT & $3 / 0.1$ & $53.7 \%\left(\Delta \mathrm{R} / \mathrm{R}_{0}\right)$ & $14 \mathrm{~min} /-$ & [90] \\
\hline & ZIF-8-8 ${ }^{1}$ & Chemoresistive & $350^{\circ} \mathrm{C}, 5 \mathrm{~V}$ & $100 /-$ & $\sim 118.5\left(\mathrm{R}_{\mathrm{g}} / \mathrm{R}_{\mathrm{a}}\right)$ & $\begin{array}{c}113.5 \mathrm{~s} / 111.5 \\
\mathrm{~s}\end{array}$ & [91] \\
\hline \multirow{8}{*}{$\mathrm{H}_{2} \mathrm{~S}$} & MIL-100(In) $^{2}$ & Optical & $40^{\circ} \mathrm{C}$ & $3 / 0.535$ & $2200(\mathrm{PL}) *$ & 1 & [92] \\
\hline & fum-fcu-MOF & Capacitive & RT & $1 / 0.0054$ & $\begin{array}{l}8.8 \times 10^{-4} \\
(\Delta \mathrm{c} / \mathrm{c})\end{array}$ & $\backslash$ & [93] \\
\hline & ZIF-8/ZnO & Chemoresistive & RT & $1 / \leq 0.05$ & $18.7 \%\left(\Delta \mathrm{R} / \mathrm{R}_{0}\right)$ & $\begin{array}{l}7 \mathrm{~min} / 10.7 \\
\min \end{array}$ & [94] \\
\hline & $\mathrm{MOF}-5 / \mathrm{CS} / \mathrm{IL}^{3}$ & Chemoresistive & $\mathrm{RT}, 120 \mathrm{mV}$ & $100 / 1$ & $98 \%\left(R_{a} / R_{g}\right)$ & $<8 \mathrm{~s} / \sim 30 \mathrm{~s}$ & [95] \\
\hline & $\mathrm{Cu}_{3}(\mathrm{HHTP})_{2}$ & Chemoresistive & RT & $80 / 0.52$ & $98 \%\left(-\Delta G / G_{0}\right)$ & $\begin{array}{l}5 \min / 10 \\
\min e^{e}\end{array}$ & [96] \\
\hline & $\mathrm{Ni}_{3}(\mathrm{HHTP})_{2}$ & Chemoresistive & RT & $80 / 0.23$ & $97 \%\left(-\Delta G / G_{0}\right)$ & $5 \min _{\min } \mathrm{e}^{10}$ & [96] \\
\hline & $\mathrm{NiPc}-\mathrm{Ni}^{4}$ & Chemoresistive & $\begin{array}{c}\mathrm{RT}, 0.01-1.0 \\
\mathrm{~V}\end{array}$ & $80 / 0.032$ & $64 \%\left(-\Delta G / G_{0}\right)$ & $\underset{\min ^{2}}{2.3 \min / 10}$ & [97] \\
\hline & $\mathrm{NiPc}-\mathrm{Cu}{ }^{4}$ & Chemoresistive & $\begin{array}{c}\text { RT, } 0.01-1.0 \\
\text { V }\end{array}$ & $80 / 0.019$ & $98 \%\left(-\Delta G / G_{0}\right)$ & $\begin{array}{c}1.3 \min / 10 \\
\min ^{\mathrm{e}}\end{array}$ & [97] \\
\hline
\end{tabular}


Table 1. Cont.

\begin{tabular}{|c|c|c|c|c|c|c|c|}
\hline Gas & Materials & Sensor Type & $\begin{array}{l}\text { Working } \\
\text { Cond. }\end{array}$ & $\begin{array}{c}\text { Con./LOD } \\
(\mathrm{ppm})\end{array}$ & Response \#\# & $\mathrm{T}_{\mathrm{res}} / \mathrm{T}_{\mathrm{rec}} \$ \$$ & Ref. \\
\hline \multirow{6}{*}{$\mathrm{SO}_{2}$} & MOF-5- $\mathrm{NH}_{2}$ & Optical & $\begin{array}{l}\text { RT, UV (365 } \\
\text { nm) }\end{array}$ & $2 / 0.05$ & $\begin{array}{l}\text { Luminescence } \\
\text { turn-on }\end{array}$ & $15 \mathrm{~s} /-$ & [98] \\
\hline & Eu-BDC-NH ${ }_{2}{ }^{5}$ & Optical & $\begin{array}{l}\text { RT, UV (370 } \\
\text { nm) }\end{array}$ & $10 / 0.65$ & $7340(\mathrm{PL})$ * & $6 \mathrm{~s} /-$ & [99] \\
\hline & UiO-66- $\mathrm{NH}_{2}$ & Capacitive & RT & $50 /-$ & \multirow{2}{*}{$\begin{array}{c}23 \times 10^{-4}(\Delta \mathrm{c} / \mathrm{c}) \\
17 \times 10^{-4}(\Delta \mathrm{c} / \mathrm{c}) \\
*\end{array}$} & $185 \mathrm{~s} /-$ & [28] \\
\hline & MFM-300(In) & Capacitive & $\mathrm{RT}\left(22^{\circ} \mathrm{C}\right)$ & $1 / 0.005$ & & $\backslash$ & [100] \\
\hline & $\mathrm{NH}_{2}$-UiO-66 & Chemoresistive & $150^{\circ} \mathrm{C}$ & $10 / 1$ & $21.6 \%\left(\Delta \mathrm{R} / \mathrm{R}_{0}\right)$ & $26.8 \mathrm{~s} / 41.6 \mathrm{~s}$ & [101] \\
\hline & $\begin{array}{l}\text { Ni-MOF/-OH- } \\
\text { SWNTs }\end{array}$ & Chemoresistive & RT & $1 / 0.5$ & $0.9784\left(\Delta \mathrm{R} / \mathrm{R}_{0}\right)$ & $10 \mathrm{~s} / 30 \mathrm{~s}$ & [102] \\
\hline \multirow{5}{*}{$\mathrm{CO}_{2}$} & ZIF-8 & Optical & $\begin{array}{l}\text { RT, UV ( } 242 \\
n m)\end{array}$ & $60 \% /-$ & $72 \%(\mathrm{~T} \%)^{*, \mathrm{f}}$ & $14 \mathrm{~s} / 9 \mathrm{~s}$ & [103] \\
\hline & Mg-MOF-74 & Capacitive & RT & $1000 /-$ & $\begin{array}{c}2.1 \times 10^{-4} \\
(\Delta \mathrm{c} / \mathrm{c})^{*}\end{array}$ & 1 & [9] \\
\hline & $\mathrm{NH}_{2}-\mathrm{UiO}-66(\mathrm{Zr})$ & Chemoresistive & $150^{\circ} \mathrm{C}$ & $5000 /-$ & $11.4 \%\left(\Delta \mathrm{R} / \mathrm{R}_{0}\right)$ & 1 & [101] \\
\hline & $\mathrm{Cu}_{3}(\mathrm{HIB})_{2}$ & Chemoresistive & RT & $\begin{array}{c}400- \\
2500 / 67\end{array}$ & $0.62 \%\left(\Delta \mathrm{G} / \mathrm{G}_{0}\right)$ & $\begin{array}{c}7-8 \\
\min / 10-11 \\
\min \end{array}$ & [104] \\
\hline & $\mathrm{SnO}_{2} @ Z I F-67$ & Chemoresistive & $205^{\circ} \mathrm{C}$ & $5000 /-$ & $16.5 \%\left(\Delta \mathrm{R} / \mathrm{R}_{0}\right)$ & $96 \mathrm{~s} / 25 \mathrm{~s}$ & [105] \\
\hline \multirow{10}{*}{$\mathrm{NH}_{3}$} & \multirow{2}{*}{$\begin{array}{c}\text { MIL- } \\
124 @ \mathrm{Eu}^{3+} / \mathrm{Al}_{2} \mathrm{O}_{3} \\
\text { NDC-Y-fcu-MOF }\end{array}$} & Optical & $\begin{array}{c}\text { RT, UV (298 } \\
\text { nm) }\end{array}$ & $500 / 26.2$ & $0.14(\Delta \mathrm{PL} / \mathrm{PL}) *$ & $\backslash$ & [106] \\
\hline & & Capacitive & RT & $25 / 0.092$ & $7 \times 10^{-4}(\Delta \mathrm{c} / \mathrm{c})$ * & $\sim 250 \mathrm{~s} /$ & [107] \\
\hline & $\mathrm{NiPc}_{\mathrm{C}} \mathrm{M}^{7}$ & Chemoresistive & $\begin{array}{c}\text { RT, 0.01-1.0 } \\
\text { V }\end{array}$ & $80 / 0.05$ & $\begin{array}{c}43-45 \% \\
\left(-\Delta G / G_{0}\right)\end{array}$ & $2.3-1.3 \mathrm{~min} /-$ & [97] \\
\hline & $\mathrm{Cu}-\mathrm{BHT}^{8}$ & Chemoresistive & RT, $0.01 \mathrm{~V}$ & $20 / 0.23$ & $7.88 \%\left(\Delta \mathrm{R} / \mathrm{R}_{0}\right)$ & $58 \mathrm{~s} / 102 \mathrm{~s}$ & [108] \\
\hline & $\mathrm{Cu}_{3}(\mathrm{HITP})_{2}$ & Chemoresistive & RT, $0.1 \mathrm{~V}$ & 2/- & $0.48 \%\left(\Delta \mathrm{G} / \mathrm{G}_{0}\right)$ & 1 & [109] \\
\hline & Cu-HHTP & Chemoresistive & RT & $\begin{array}{c}100 / 8.7 \times \\
10^{-5}\end{array}$ & $161 \%\left(R_{a} / R_{g}\right)$ & $35 \mathrm{~s} / 15 \mathrm{~min}$ & [110] \\
\hline & Pd-Co@IRMOF1 9 & Chemoresistive & RT & $90 / 1$ & $80.17\left(\mathrm{R}_{\mathrm{a}} / \mathrm{R}_{\mathrm{g}}\right)$ & $46 \mathrm{~s} / 22 \mathrm{~s}$ & [111] \\
\hline & $\mathrm{Zn}(\mathrm{NA})^{10}$ & Chemoresistive & RT & $100 /-$ & $220\left(\mathrm{R}_{\mathrm{a}} / \mathrm{R}_{\mathrm{g}}\right)^{\prime}$ & $46 \mathrm{~s} / 200 \mathrm{~s}$ & [112] \\
\hline & SNNU-88 ${ }^{11}$ & Chemoresistive & RT & $50 /-$ & $2.3\left(\mathrm{R}_{\mathrm{a}} / \mathrm{R}_{\mathrm{g}}\right)$ & $87 \mathrm{~s} / 127 \mathrm{~s}$ & [113] \\
\hline & $\mathrm{Cu}_{3}(\mathrm{BTC})_{2} / \mathrm{GO}^{12}$ & Chemoresistive & $\mathrm{RT}, 1 \mathrm{~V}$ & $100 /-$ & $4\left(\mathrm{R}_{\mathrm{a}} / \mathrm{R}_{\mathrm{g}}\right)$ & 1 & [114] \\
\hline
\end{tabular}

\#\# In the Response column: " $\Delta$ " represents difference; PL, R, G and c correspond to intensity of photoluminescence emission, electric resistance, current, and capacitance, respectively; subscripts of " 0 ", " $a$ " and " $\mathrm{g}$ " refer to the initial state, in air and in target gas, respectively. $\$ \$ \mathrm{~T}_{\text {res }}$ and $\mathrm{T}_{\text {rec }}$ are the sensor response and recovery time, respectively. ${ }^{*}$ Estimated value, data is unavailable. ${ }^{\mathrm{a}}$ Time for emission peak $(543 \mathrm{~nm})$ to reach its plateau. ${ }^{\mathrm{b}}$ Time for $\sim 20 \%$ increase in PL after exposure to target gas. ${ }^{\mathrm{c}} 2 \mathrm{~min}$ is for current increased from $30 \mathrm{nA}$ to $2 \mu \mathrm{A}$, and $42 \mathrm{~s}$ is for current decreased from $55 \mu \mathrm{A}$ to $30 \mathrm{nA} \cdot{ }^{\mathrm{d}} \mathrm{R}_{1}$ and $\mathrm{R}_{2}$ correspond to the resistance of M-MOF-74 before and after exposure to target gas. ${ }^{\mathrm{e}}$ Time for purging the target gas $\left(\mathrm{H}_{2} \mathrm{~S}\right)$ and dry $\mathrm{N}_{2}$ respectively. ${ }^{\mathrm{f}} \% \mathrm{~T}=$ transmittance. ${ }^{1}$ The ZIF-8 was synthesised at a molar ratio of 8:1 for $\mathrm{Zn}\left(\mathrm{NO}_{3}\right)_{2} \cdot 6 \mathrm{H}_{2} \mathrm{O}$ and 2-methylimidazole. ${ }^{2}$ MIL-100(In) $=\operatorname{In}_{3} \mathrm{O}(\mathrm{OH})\left(\mathrm{H}_{2} \mathrm{O}\right)_{2}[\mathrm{BTC}]_{2}$, where indium is the metal node and BTC (1,3,5-benzenetricarboxylic acid) is the ligand. ${ }^{3} \mathrm{MOF}-5\left(\left[\mathrm{Zn}_{4} \mathrm{O}(\mathrm{BDC})_{3}\right]_{\mathrm{n}}\right)$ microplates embedded on an organic membrane of chitosan (CS) blended with glycerol ionic liquid (IL). ${ }^{4} \mathrm{NiPc}=$ nickel phthalocyanine. ${ }^{5}$ Eu-BDC- $\mathrm{NH}_{2}\left(\mathrm{H}_{2} \mathrm{BDC}-\mathrm{NH}_{2}\right.$, 2-aminoterephthalic acid), where BDC $=1$,4-benzodicarboxylate. ${ }^{6} \mathrm{NDC}-\mathrm{Y}$-fcu-MOF $=$ Naphthalene (NDC) based RE-fcu-MOF, fcu is short for face-centred cubic. ${ }^{7} \mathrm{M}=\mathrm{Ni}, \mathrm{Cu} .{ }^{8} \mathrm{BHT}=$ benzenehexathiol. ${ }^{9} \mathrm{IRMOF}-1$ (MOF-5) is a metal-organic framework compound with the formula of $\mathrm{Zn}_{4} \mathrm{O}(\mathrm{BDC})_{3}$. ${ }^{10} \mathrm{NA}=$ nicotinic Acid. ${ }^{11} \mathrm{SNNU}-88=\left\{\left[\left(\mathrm{CH}_{3}\right)_{2} \mathrm{NH}_{2}\right]\left[\mathrm{Mg}_{3}(\mathrm{OH})(\mathrm{DHBDC})_{3}(\mathrm{TPP})\right]_{\mathrm{n}}\right.$; where SNNU = Shaanxi Normal University, and $\mathrm{TPP}=2,4,6$-tri(4-pyridyl)pyridine. ${ }^{12} \mathrm{BTC}=$ benzene tricarboxylic, $\mathrm{GO}=$ graphene oxide.

\section{Nitrogen Dioxide $\left(\mathrm{NO}_{2}\right)$}

Among the most common pollutants, $\mathrm{NO}_{2}$ is a harmful gas that is generated by combustion processes at high temperatures and requires to be monitored in order to control its release [115]. $\mathrm{NO}_{2}$ is the main source of nitric acid aerosol leading to smog and acid rain; in humans, it can cause inflammation of the airways and can even cause death at high concentrations $[116,117]$. Therefore, there is great demand for highly sensitive, selective, cost-effective, rapid and reliable, non-invasive techniques for monitoring $\mathrm{NO}_{2}$.

Monitoring the optical emission changes of the MOF pre- and post- $\mathrm{NO}_{2}$ exposure provides an interesting route for the utilization of MOF-based materials in gas-sensing 
applications. Luminescent MOFs (LMOFs) are widely used in gas sensing because of their excellent optical response towards guest molecules inside their cavities. Gas sensors, fabricated using two lanthanide-based MOFs (Tb-MOF and Eu-MOF, formed by 2-amino-1,4-benzene dicarboxylic acid with europium and terbium salts, respectively), were reported by Gamonal et al. [84] for $\mathrm{NO}_{2}$ gas detection with an LOD of $2.2 \mathrm{ppm}$ at room temperature. The sensing mechanism was based on the rise in $\mathrm{Eu}^{3+}$ luminosity and the reduction in $\mathrm{Tb}^{3+}$ luminescence upon exposure to $\mathrm{NO}_{2}$ gas. Zhang et al. [118] demonstrated a direct correlation between the fluorescence intensity of the ZJU-66-based sensor and $\mathrm{NO}_{2}$ concentrations. Similarly, Moscoso et al. [119] developed Tb-based MOF films, so-called Tb(BTC)@PDMS (BTC: benzene-1,3,5tricarboxylate, PDMS: polydimethylsiloxane), where the photoluminescent frequency of the film was gradually decreased as the $\mathrm{NO}_{2}$ concentration was increased from 0 to $500 \mathrm{ppm}$.

A combination of colorimetric and chemoresistive MOF detectors (MOF A, with Co and octadentate calix[4]-resorcinarene as the metallic centre and ligand, respectively) was synthesised by Ma et al. [90] using a solvothermal approach. The sensing mechanism was based on the absorption of $\mathrm{NO}_{2}$ gas molecules onto the surface of MOF A. The O atoms of the absorbed $\mathrm{NO}_{2}$ interacted primarily with the adjacent carboxylic groups and coordinating water through hydrogen-bonding interactions, leading to the formation of a conductive pathway. Another conductive pathway may be formed by the $\mathrm{NO}_{2}$ molecule and $\mathrm{H}_{3} \mathrm{O}^{+}$through hydrogen-bonding interactions (Figure $1 \mathrm{~b}$, inset), resulting in an eight orders of magnitude enhancement for conductivity where the resistance of MOF A decreased from $5.7 \times 10^{11} \Omega$ to $9.1 \times 10^{3} \Omega$ upon exposure to $\mathrm{NO}_{2}$ gas molecules (Figure $1 \mathrm{~b}$ ). In addition to the electrical sensing response, a visible change in the colour was observed in MOF A where the crystal colour changed from red to yellow after $\mathrm{NO}_{2}$ exposure (Figure 1a).

In a similar gas molecule absorption approach, Gallis et al. [32] reported the $\mathrm{NO}_{\mathrm{x}}$ adsorption behaviour of Y-DOBDC-based MOF (yttrium-2,5-dihydroxyter-ephthalic acid) by analysing its photoluminescence (PL) characteristics in both pre- $\mathrm{NO}_{\mathrm{x}}$ and post-NO $\mathrm{N}_{\mathrm{x}}$ exposures. As demonstrated in Figure 1c, the colour of synthesised Y-DOBDC-based MOF changed from pale yellow to vibrant brown-orange after NOx exposure for $24 \mathrm{~h}$ under visible light. In addition, a significant reduction in the emission intensity of all compounds was observed under UV light illumination $(350 \mathrm{~nm})$ after $24 \mathrm{~h}$ exposure (Figure 1d), indicating the interaction between the DOBDC ligand in Y-DOBDC and $\mathrm{NO}_{2}$ molecules (Figure 1d, inset). Observed and detectable optical signals upon the absorption of $\mathrm{NO}_{2}$ gas provided a unique and direct means for $\mathrm{NO}_{2}$ detection; however, quantitative analysis of the variable of $\mathrm{NO}_{2}$ concentration was not addressed in detail [85].

Liu et al. [87] reported an $\operatorname{In}_{2} \mathrm{O}_{3}$ /ZIF-8 (ZIF-8: zeolitic imidazolate framework-8, where $\mathrm{Zn}$ and 2-methylimidazole are the metal node and ligand, respectively) nanocomplex for ppb-level $\mathrm{NO}_{2}$ gas detection, with enhanced humidity resistance due to the hydrophobic nature of the self-templated ZIF-8 nanoparticles on the surface of $\operatorname{In}_{2} \mathrm{O}_{3}$ nanofibers. The synthesis procedure involved electrospinning and subsequent calcination in the air to fabricate $\mathrm{In}_{2} \mathrm{O}_{3} / \mathrm{ZnO}$, which was not only used as the $\mathrm{Zn}^{2+}$ source for subsequent $\mathrm{ZIF}$ 8 solvothermal growth on the surface of $\operatorname{In}_{2} \mathrm{O}_{3}$ nanofibers (Figure 2a,b) but also as the template for the $\mathrm{In}_{2} \mathrm{O}_{3} / \mathrm{ZIF}-8$ nanocomplex. Different microstructures of the $\mathrm{In}_{2} \mathrm{O}_{3} / \mathrm{ZIF}$ 8 nanohybrid were prepared by tuning the molar ratios of $\mathrm{In}$ and $\mathrm{Zn}$ from 8:1 to 2:1 (Figure 2c-e) where ZIF-8 NPs ( $80-100 \mathrm{~nm}$ in diameter) were attached to the surface of the $\mathrm{In}_{2} \mathrm{O}_{3}$ nanofibers. 

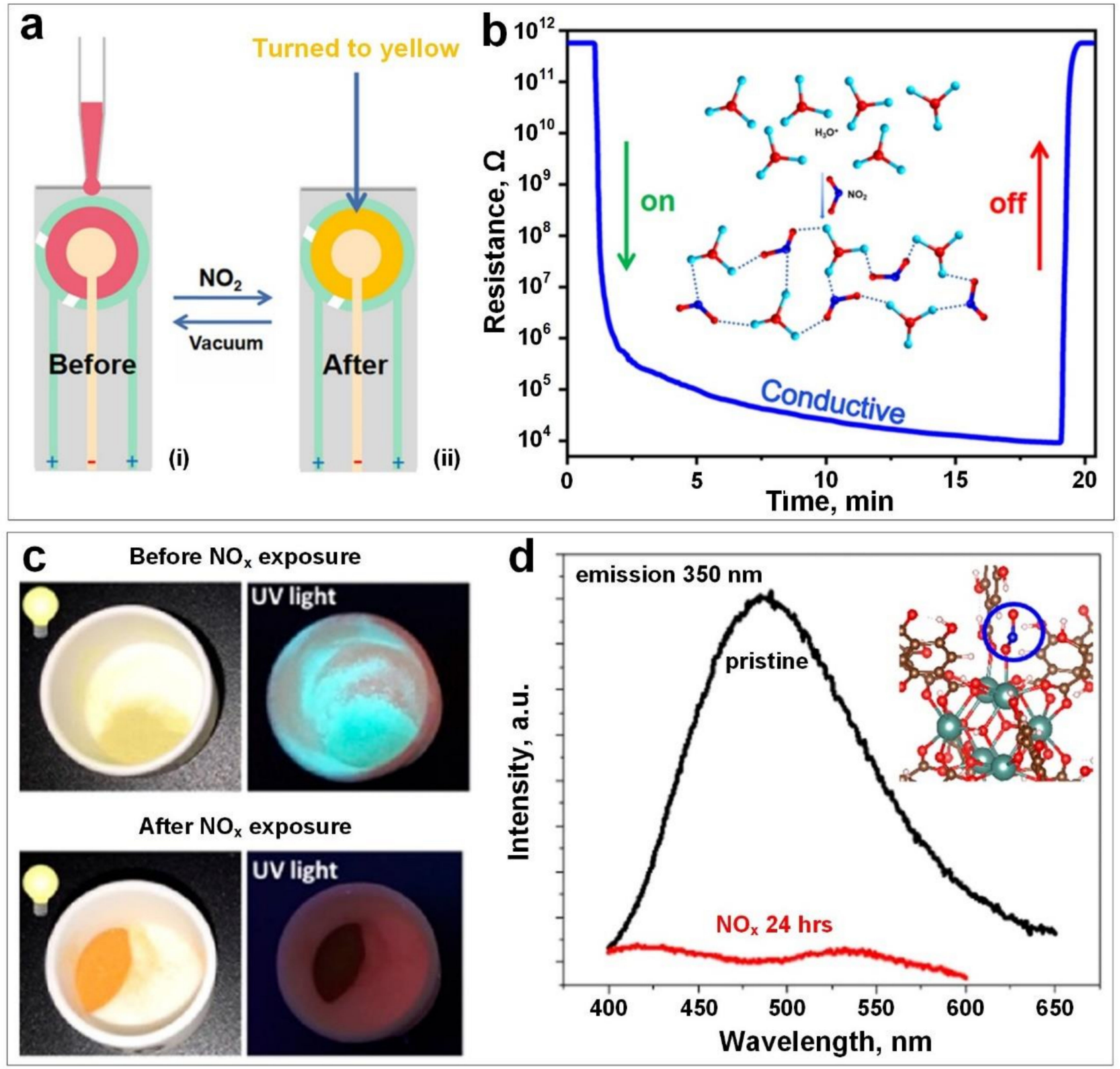

Figure 1. (a) The colour change in a gold electrode sheet covered by MOF A before and after $\mathrm{NO}_{2}$ exposure. (b) The resistance variation versus time upon $\mathrm{NO}_{2}$ exposure. Reproduced with permission from [85] American Chemical Society, 2021. (c) The colour change of Y-DOBDC before and after exposure to $\mathrm{NO}_{\mathrm{x}}$ under visible and UV light. (d) Photoluminescent intensity of $\mathrm{Y}$-DOBDC before and after $24 \mathrm{~h}$ exposure to $\mathrm{NO}_{\mathrm{x}}$, and the guest-framework interactions (Inset). Reproduced with permission from [32] American Chemical Society, 2019. 


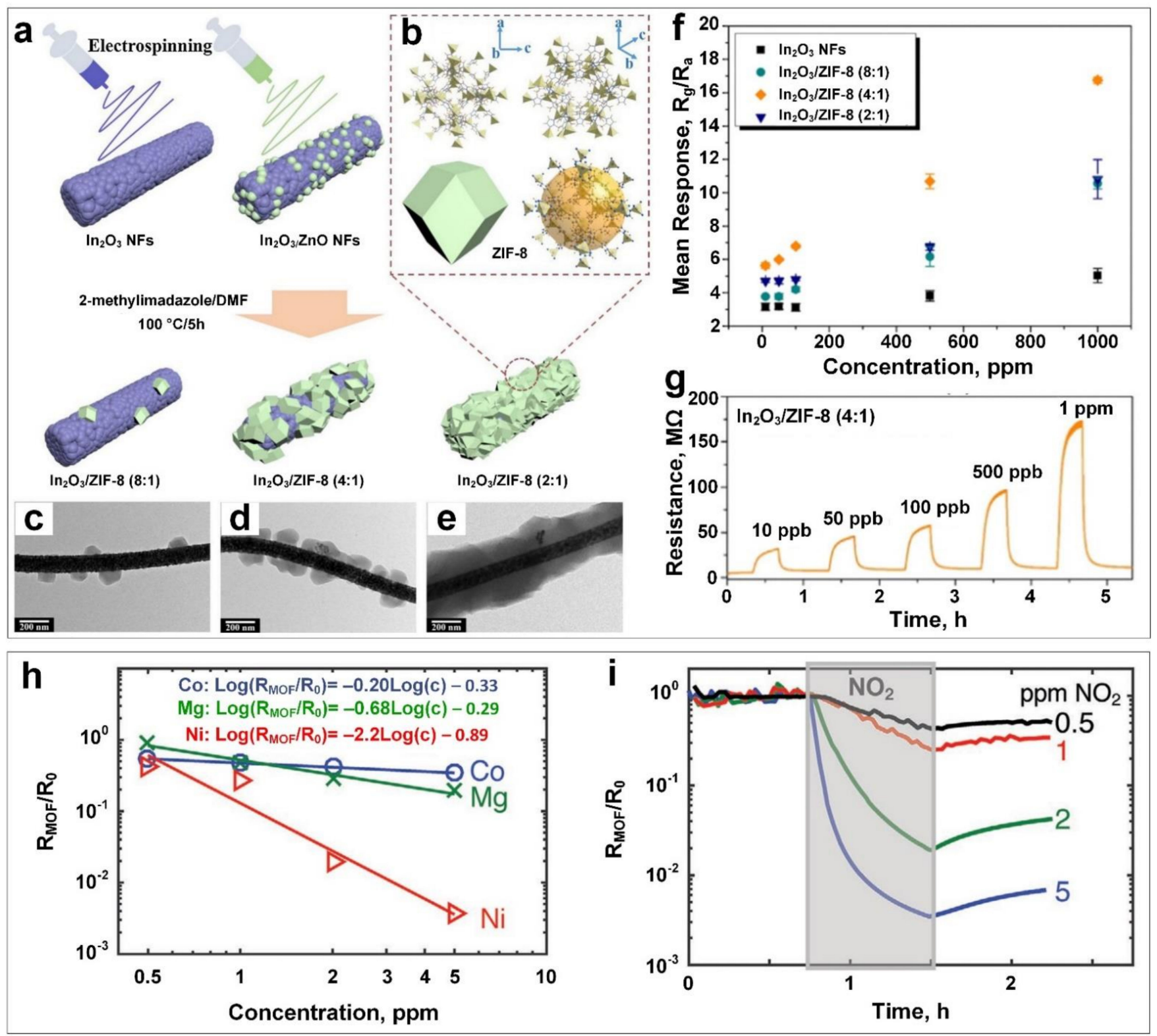

Figure 2. (a) Schematic diagram of $\mathrm{In}_{2} \mathrm{O}_{3} / \mathrm{ZIF}-8$ nanocomposite fabrication. (b) ZIF-8 structure. TEM images of $\mathrm{In}_{2} \mathrm{O}_{3} / \mathrm{ZIF}-8$ (8:1) (c), $\mathrm{In}_{2} \mathrm{O}_{3} / \mathrm{ZIF}-8$ (4:1) (d), and $\mathrm{In}_{2} \mathrm{O}_{3} / \mathrm{ZIF}-8$ (2:1) (e). (f) Mean response versus concentration for pure $\mathrm{In}_{2} \mathrm{O}_{3}$ and its composites with ZIF-8. (g) Typical dynamic response curves of $\operatorname{In}_{2} \mathrm{O}_{3} /$ ZIF-8 (4:1) sensors towards $\mathrm{NO}_{2}$ gas at different concentrations at $140{ }^{\circ} \mathrm{C}$. Reproduced with permission from [87] Elsevier, 2019. (h) The relationship of response versus $\mathrm{NO}_{2}$ gas concentration for different $\mathrm{M}-\mathrm{MOF}-74(\mathrm{M}=\mathrm{Co}, \mathrm{Mg}, \mathrm{Ni})$. (i) The dynamic response curves of $\mathrm{M}-\mathrm{MOF}-74$ for exposure to $0.5,1,2$ and $5 \mathrm{ppm} \mathrm{NO} 2$ gas at $50^{\circ} \mathrm{C}$. Reproduced with permission from [86] Wiley-VCH, 2020.

The fabricated $\mathrm{In}_{2} \mathrm{O}_{3} / \mathrm{ZIF}-8$ with a molar ratio of 4:1 (In: $\mathrm{Zn}$ ) demonstrated the highest sensing response among all the $\mathrm{In}_{2} \mathrm{O}_{3} / \mathrm{ZIF}-8$ nanocomposites (and pure $\mathrm{In}_{2} \mathrm{O}_{3}$ ) within the $\mathrm{NO}_{2}$ concentration range of $10 \mathrm{ppb}$ to $1 \mathrm{ppm}$ at an optimal operating temperature of $140{ }^{\circ} \mathrm{C}$ (Figure $2 \mathrm{f}$ ). A sensing response of 16.4 was achieved for $\mathrm{In}_{2} \mathrm{O}_{3} / \mathrm{ZIF}-8$ (4:1) at 1 ppm $\mathrm{NO}_{2}$ concentration compared to $10.7,10.4$ and 4.9 for $\mathrm{In}_{2} \mathrm{O}_{3} / \mathrm{ZIF}-8$ (2:1), $\mathrm{In}_{2} \mathrm{O}_{3} / \mathrm{ZIF}$ 8 (8:1) and $\mathrm{In}_{2} \mathrm{O}_{3}$ respectively. For a typical dynamic $\mathrm{NO}_{2}$ gas-sensing curve based on $\mathrm{In}_{2} \mathrm{O}_{3} / \mathrm{ZIF}-8$ (4:1) (Figure 2g), a well-defined increasing resistance trend was reported with increasing $\mathrm{NO}_{2}$ gas concentration. In addition, rapid response kinetics of $80 \mathrm{~s}$ and 133 $\mathrm{s}$ for response and recovery time, respectively, were achieved for the $\operatorname{In}_{2} \mathrm{O}_{3} / \mathrm{ZIF}-8$ (4:1) 
nanosensor, demonstrating that $\mathrm{In}_{2} \mathrm{O}_{3} / \mathrm{ZIF}-8$ (4:1) is a promising nanostructured candidate for the fast detection of $\mathrm{NO}_{2}$ gas down to $10 \mathrm{ppb}$ at an operating temperature of $140{ }^{\circ} \mathrm{C}$.

Using a different approach, a macroscale $\left(\sim 35 \mathrm{~mm}^{2}\right)$ capacitive M-MOF-74-based sensor (formed by divalent metallic cations with the organic ligand of 2,5- dihydroxyterephthalic acid) was designed by Small et al. [86] via a solvothermal synthesis technique for $\mathrm{NO}_{2}$ gas sensing at $50{ }^{\circ} \mathrm{C}$ with a near-zero power consumption of $2.25 \mathrm{pW}$. The sensing performance of the fabricated device towards $\mathrm{NO}_{2}$ gas concentrations of 0.5 to 5 ppm was investigated as a function of metal centres in the synthesised MOF-74 (i.e., Ni, Co, $\mathrm{Mg}$ ). As illustrated in Figure 2h, the Ni-based sensor (Ni-MOF-74) demonstrated the largest change in the film resistance and consequently a higher sensing response towards $\mathrm{NO}_{2}$ gas at different concentrations. However, the fabricated device suffered from very slow response dynamics and irreversible sensing performances (Figure 2i), hindering its real-world application. The former could be attributed to its high resistance change (orders of magnitude) upon $\mathrm{NO}_{2}$ exposure and the significantly large crystallite size of Ni-MOF-74 (up to 100's of $\mu \mathrm{m}$ ), making the difference in mass transport of $\mathrm{NO}_{2}$ less dominant at short time intervals. The issue of prolonged recovery time towards $\mathrm{NO}_{2}$ gas sensing might be addressed by using a photoactivation approach [88].

Catalytic metal nanoparticles (NPs, e.g., Au, Pd and Pt) have long been proved to boost the gas-sensing performance chemoresistively [120-122]. Taking advantage of selfassembled highly porous 2D conductive MOFs with tuneable cavity size, Koo et al. [89] introduced well-dispersed Pd and Pt NPs to solvothermally fabricated $\mathrm{Cu}_{3}$ (hexahydroxytri phenylene $)_{2}\left(\mathrm{Cu}_{3}(\mathrm{HHTP})_{2}\right)$ with $2 \mathrm{~nm}$ cavities (Figure 3a). Upon exposure to $5 \mathrm{ppm} \mathrm{NO}_{2}$, both $\mathrm{Cu}_{3}(\mathrm{HHTP})_{2}$ and $\mathrm{M} @ \mathrm{Cu}_{3}(\mathrm{HHTP})_{2}(\mathrm{M}=\mathrm{Pd}, \mathrm{Pt})$ exhibited p-type semiconducting characteristics, with a significantly higher sensing response (about two times higher) for both $\mathrm{Pd} @ \mathrm{Cu}_{3}(\mathrm{HHTP})_{2}$ and $\mathrm{Pt} @ \mathrm{Cu}_{3}(\mathrm{HHTP})_{2}(62.11 \%$ and $57.38 \%$, respectively) compared to the pure $\mathrm{Cu}_{3}(\mathrm{HHTP})_{2}$ (response of 29.95\%) (Figure 3c). This higher sensing performance could be attributed to the electronic sensitization mechanism resulting from the lowering of potential barriers at Schottky junctions between metallic NPs and $\mathrm{Cu}_{3}(\mathrm{HHTP})_{2}$ as $\mathrm{NO}_{2}$ molecules were absorbed on the surface (Figure $3 b$ ). The reduced sensing performance of the Pt-based sensing material could be attributed to the higher $\mathrm{NO}_{2}$ adsorption and desorption kinetics of Pt-decorated MOF $\left(5.54 \times 10^{-2} \mathrm{ppm}^{-1} \cdot \mathrm{s}^{-1}\right.$ and $7.30 \times 10^{-5} \mathrm{ppm}^{-1} \cdot \mathrm{s}^{-1}$ for adsorption and desorption, respectively) compared to those of Pd-decorated MOF $\left(2.51 \times 10^{-2} \mathrm{ppm}^{-1} \cdot \mathrm{s}^{-1}\right.$ and $5.10 \times 10^{-5} \mathrm{ppm}^{-1} \cdot \mathrm{s}^{-1}$ for adsorption and desorption, respectively). 
a

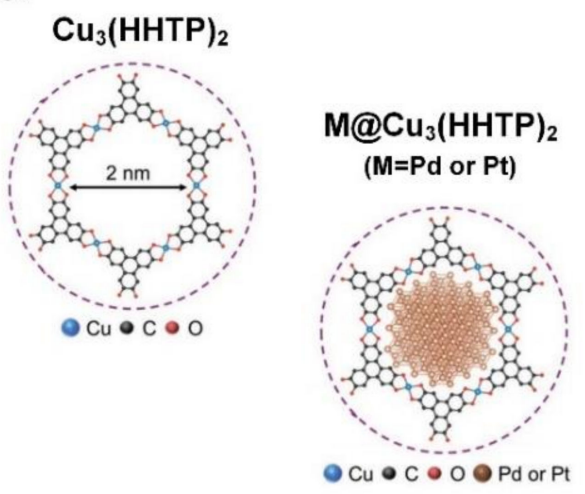

b

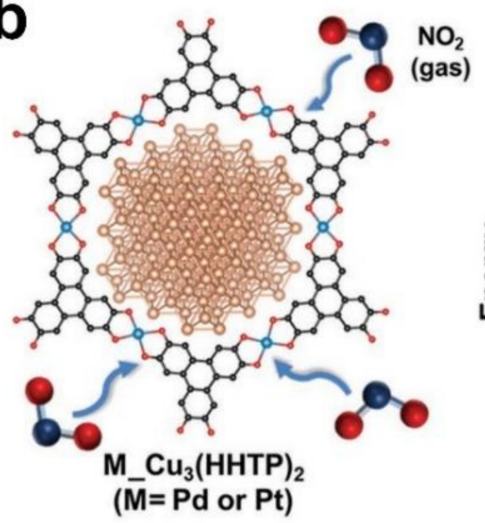

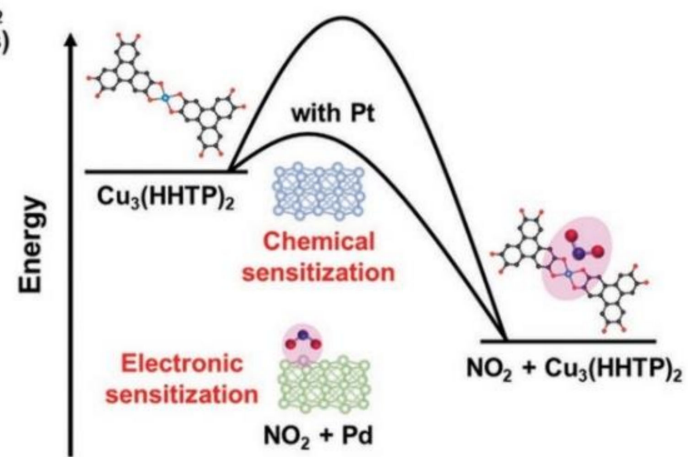
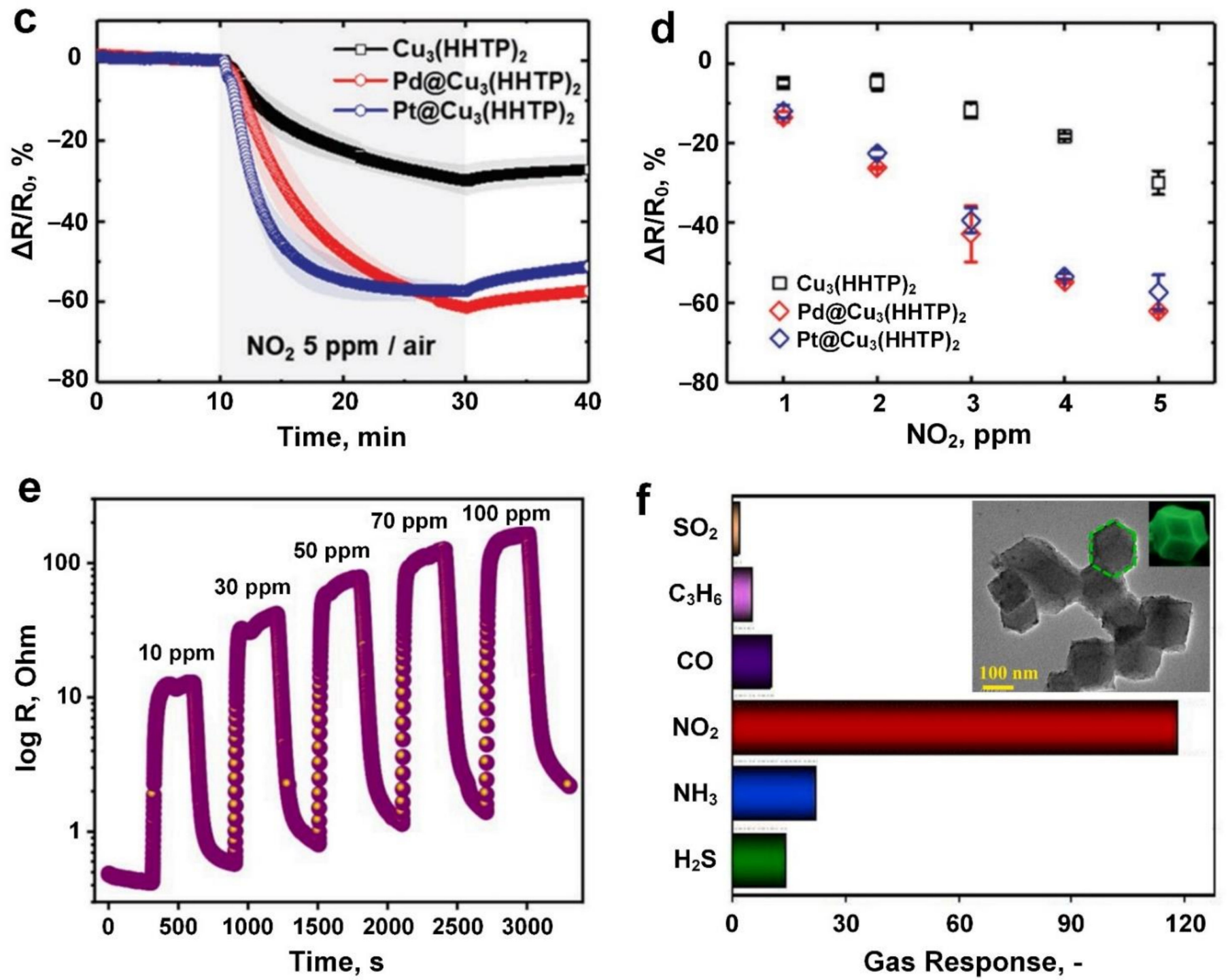

Figure 3. (a) Schematic of $\mathrm{Cu}_{3}(\mathrm{HHTP})_{2}$ and $\mathrm{M} @ \mathrm{Cu}_{3}(\mathrm{HHTP})_{2}$ structures, and (b) the sensing mechanism towards $\mathrm{NO}_{2}$ gas. (c) The response dynamics of $\mathrm{Cu}_{3}(\mathrm{HHTP})_{2}$ and $\mathrm{M}_{\mathrm{Cu}}(\mathrm{HHTP})_{2}(\mathrm{M}=\mathrm{Pd}, \mathrm{Pt})$ sensors to 5 ppm $\mathrm{NO}_{2}$ gas, and (d) the corresponding responses for a range of $\mathrm{NO}_{2}$ concentrations. All tests were performed at room temperature in the air. Reproduced with permission from [89] Wiley, 2019. (e) The dynamic response of ZIF-8-8 sensor versus different concentrations of $\mathrm{NO}_{2}$ gas at $350{ }^{\circ} \mathrm{C}$. (f) The cross-selectivity of ZIF-8-8 sensors towards 100 ppm of different gases at $350^{\circ} \mathrm{C}$ (Inset, TEM image of nanostructured polyhedral ZIF-8-8). Reproduced with permission from [91] Elsevier, 2021. 
The sensing response increased linearly from $\sim 6 \%$ to $\sim 60 \%$ with an increase in $\mathrm{NO}_{2}$ concentration from 1 ppm to 5 ppm (Figure 3d) indicating that $\mathrm{M} @ \mathrm{Cu}_{3}(\mathrm{HHTP})_{2}(\mathrm{M}=\mathrm{Pd}, \mathrm{Pt})$ is a promising candidate for room temperature $\mathrm{NO}_{2}$ sensing applications. In addition to the

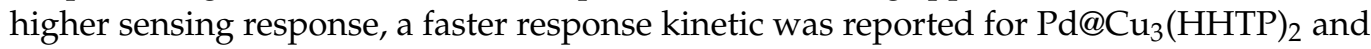
$\mathrm{Pt} @ \mathrm{Cu}_{3}(\mathrm{HHTP})_{2}$ with $13.8 \mathrm{~min}$ and $14 \mathrm{~min}$ response time, respectively, while a significantly longer response time of $>18$ min was observed for the non-NP decorated $\mathrm{Cu}_{3}(\mathrm{HHTP})_{2}$.

Recently, a novel microfluidic channel-embedded solution-shearing (MiCS) fabrication scheme was proposed for the large-area synthesis of MOF-based thin films (tens of nanometres) for the room temperature detection of $\mathrm{NO}_{2}$ gas molecules [90]. Here, similar to the blade-coating technique, a solution-to-solid transition close to the edge of the meniscus was formed between a moving blade and a heated substrate resulted in the deposition of a thin film on the substrate [123]. Applying this innovative method, $\mathrm{Pt} @ \mathrm{Cu}_{3}(\mathrm{HHTP})_{2}$ with optimized (2.3 wt.\%) Pt-loading demonstrated a superior gas sensing performance towards $\mathrm{NO}_{2}$ molecules with a high response of $89.8 \%$ and a short response time of $8.2 \mathrm{~min}$. Compared to Pt@ $\mathrm{Cu}_{3}(\mathrm{HHTP})_{2}$ fabricated previously via the conventional solvothermal method [89], the synergetic effects of large surface area and high porosity of the ultrathin MOF structure, as well as embedded nanoscopic Pt catalysts, are the major factors affecting enhanced $\mathrm{NO}_{2}$ gas sensing performance.

In another approach, ZIF-8 nanoparticles (Figure 3f, inset) were fabricated via a solvothermal method for $\mathrm{NO}_{2}$ gas sensing applications [91]. Different ratios of $\mathrm{Zn}\left(\mathrm{NO}_{3}\right)_{2} \cdot 6 \mathrm{H}_{2} \mathrm{O}$ to 2-methylimidazole from 8:1 to 64:1 were used in the synthesis of the ZIF-8 (they were named accordingly as ZIF-8-8, ZIF-8-16, ZIF-8-32 and ZIF-8-64). The fabricated ZIF-8-8 demonstrated the highest sensing response of $\sim 118.5\left(R_{g} / R_{a}\right.$, where $R_{g}$ and $R_{a}$ are the resistance of ZIF-8-8 in the target gas and air, respectively) at 100 ppm NO 2 concentration (Figure 3e), which was four-times that of other ZIF-8 based gas sensors. This higher sensing performance for ZIF-8-8 could be attributed to the larger specific surface area of ZIF-8-8 compared to ZIF-8-16, ZIF-8-32 and ZIF-8-64 nanoparticles.

In addition to high sensitivity, the fabricated ZIF-8-8 also demonstrated outstanding selectivity towards $\mathrm{NO}_{2}$ gas among a variety of gases (Figure 3f). This excellent selectivity could be attributed to the relatively low bond energy of $\mathrm{NO}_{2}\left(466 \mathrm{KJ} \cdot \mathrm{mol}^{-1}\right)$ compared to the comparatively high bond energy of other gaes (such as the bond energy of $1072 \mathrm{KJ} \cdot \mathrm{mol}^{-1}$ for CO molecules) [91]. Moreover, the sensitivity of the synthesized ZIF-8 nanomaterials was investigated over time, demonstrating an excellent stability/repeatability for the ZIF-8-8 nanosensor (compared with the other three ZIF-8 based samples) with only a $36.6 \%$ reduction in sensing response (from 112 to 71 ) after 54 days. Novel strategies such as to form hybrid nanocomposites with metal oxides (e.g., $\mathrm{In}_{2} \mathrm{O}_{3}$ [87]) could open new avenues to reduce the working temperature of current state-of-the-art technologies.

\section{Hydrogen Sulphide $\left(\mathrm{H}_{2} \mathrm{~S}\right)$}

$\mathrm{H}_{2} \mathrm{~S}$ is another air pollutant gas formed in large quantities by a range of activities, including some common large-scale activities such as sewerage processing and oil refining. In humans, $\mathrm{H}_{2} \mathrm{~S}$ can cause significant health concerns including allergic reactions and lung inflammation [124]. Despite significant advances in the design of highly sensitive $\mathrm{H}_{2} \mathrm{~S}$ gas sensors, continuous monitoring of trace-level (sub-ppm) $\mathrm{H}_{2} \mathrm{~S}$ at low operating temperatures is still challenging [125]. Given that $\mathrm{H}_{2} \mathrm{~S}$ is such a significant contaminant and is generated in several industrial applications, developing real-time sensitive and selective gas-sensing technologies for rapid detection of this gas is critical.

Zhang et al. [92] reported, for the first time, the fluorescence sensing of $\mathrm{H}_{2} \mathrm{~S}$ gas molecules through the post functionalisation of MIL-100(In) films with metal ions including $\mathrm{Eu}^{3+}$ and $\mathrm{Cu}^{2+}$ (Figure $4 \mathrm{a}, \mathrm{b}$ ). The sensing mechanism in this device was based on the reaction between $\mathrm{Cu}^{2+}$ ions and $\mathrm{H}_{2} \mathrm{~S}$ gas molecules, resulting in the activation of $\mathrm{Eu}^{3+}$ emission (Figure 4c). The fluorescence response of the MIL-100(In)@E $\mathrm{Eu}^{3+} / \mathrm{Cu}^{2+}$ film with a range of $\mathrm{H}_{2} \mathrm{~S}$ concentrations at an operating temperature of $40{ }^{\circ} \mathrm{C}$ is presented in Figure $4 \mathrm{~d}$,e. The fluorescence intensity of MIL-100(In)@Eu $\mathrm{Eu}^{3+} / \mathrm{Cu}^{2+}$ was found to increase 
steadily with the increase in $\mathrm{H}_{2} \mathrm{~S}$ level from 0 to $115 \mathrm{ppm}$ (Figure 4d), with a linear increase in the luminescence intensity as a function of $\mathrm{H}_{2} \mathrm{~S}$ level (Figure 4e), and a detection limit of $0.535 \mathrm{ppm}$.

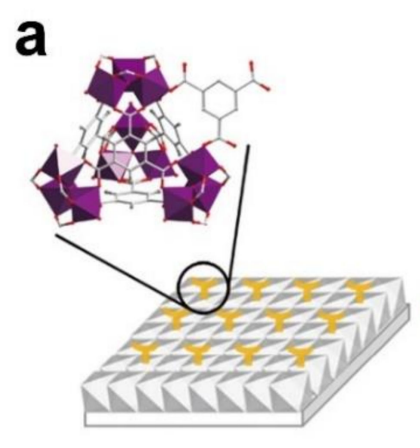

MIL-100(In) film

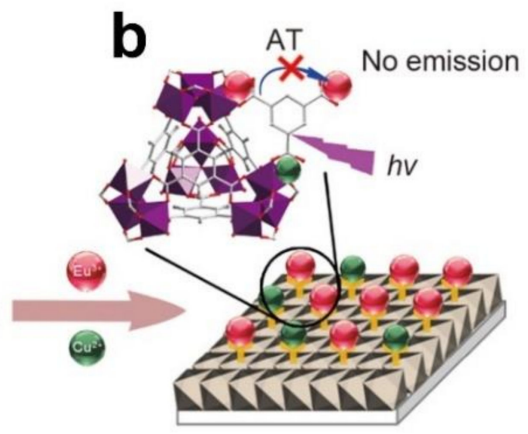

MIL-100(In)@Eu ${ }^{3+} / \mathrm{Cu}^{2+}$ film

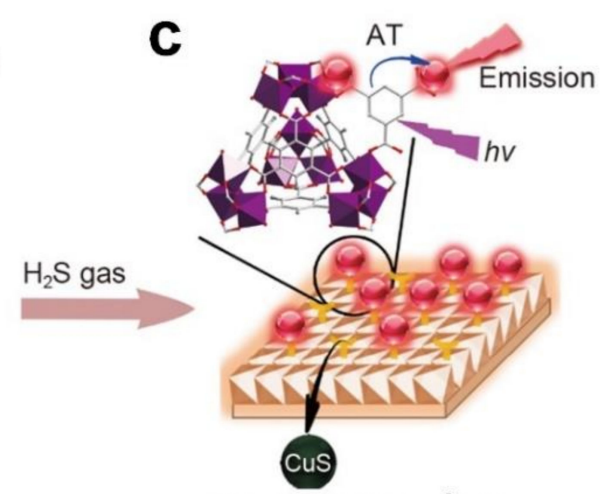

MIL-100(In)@Eu ${ }^{3+}$ film
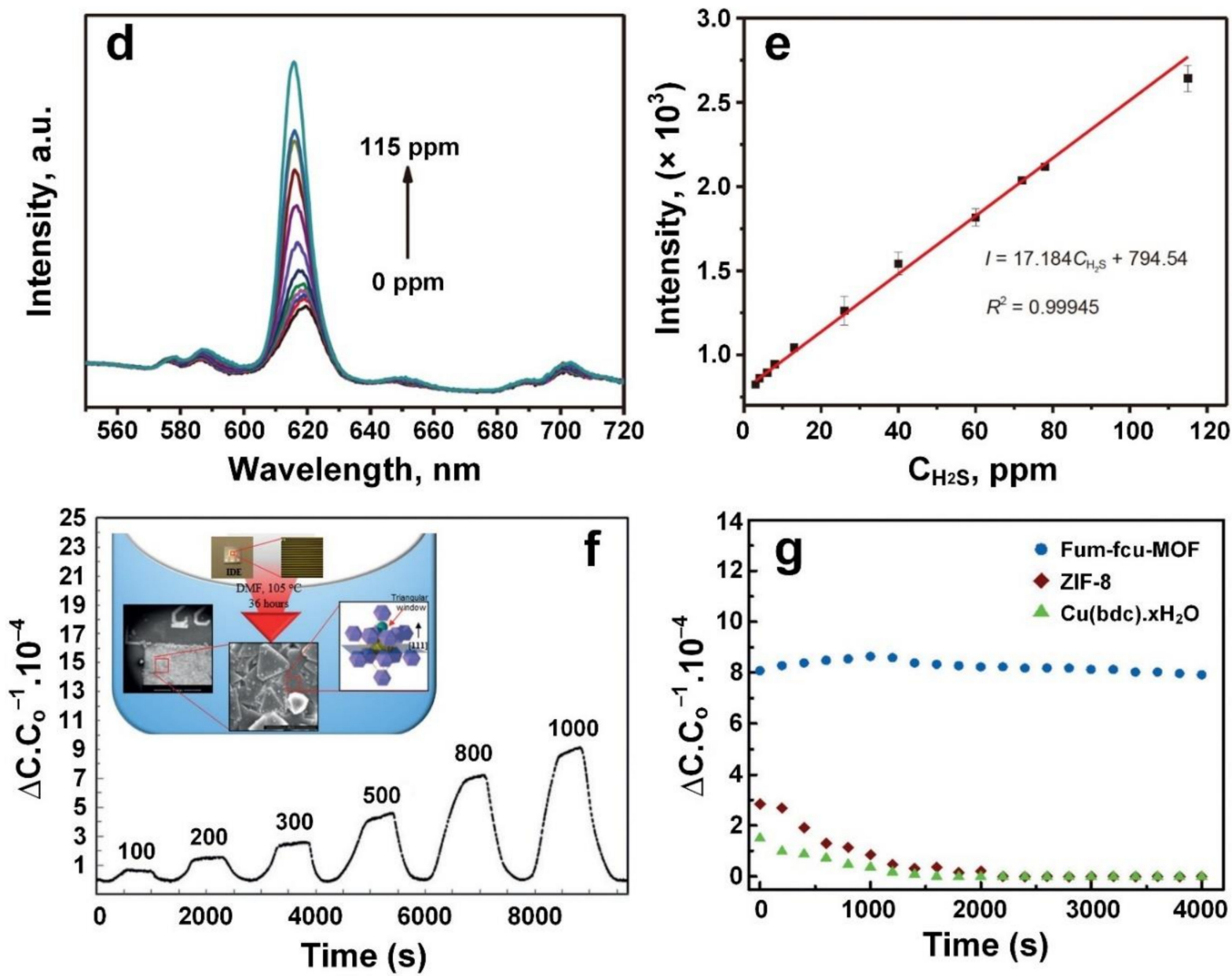

Figure 4. Schematic illustrations of MIL-100(In) based fluorescence sensor for $\mathrm{H}_{2} \mathrm{~S}$ gas detection: The MIL-100(In) film coordinating BTC ligands on the surface (a) can be functionalized by $\mathrm{Eu}^{3+} / \mathrm{Cu}^{2+}$ ions simultaneously with no emission of $\mathrm{Eu}^{3+}(\mathbf{b})$; however, the characteristic emission of $\mathrm{Eu}^{3+}$ in MIL-100(In)@E $\mathrm{Eu}^{3+} / \mathrm{Cu}^{2+}$ film could turn on with the presence of $\mathrm{H}_{2} \mathrm{~S}$ gas (c). (d,e) Fluorescence intensity versus $\mathrm{H}_{2} \mathrm{~S}$ gas at different concentrations at $40^{\circ} \mathrm{C}$. Reproduced with permission from [92] Springer, 2019. (f) The dynamic response curves of fum-fcu-MOF against $\mathrm{H}_{2} \mathrm{~S}$ gas at different concentrations, and the microstructure of fum-fcu-MOF coated on IDE (Inset). (g) The stability performance of fum-fcu-MOF against ZIF-8 and $\mathrm{Cu}(\mathrm{BDC}) \cdot \mathrm{xH}_{2} \mathrm{O}$ MOF. Reproduced with permission from [93] Wiley-VCH, 2016. 
Using a solvothermal technique and an in situ crystallisation method, Yassine et al. [93] reported the development of an isoreticular rare-earth-metal-based MOF on the surface of capacitive interdigitated electrodes (IDEs). This resulted in homogenous growth of highly oriented small crystals of fumarate-based fcu-MOF (fum-fcu-MOF, fcu is short for face-centred cubic) thin film with remarkable sensitivity towards low concentration of $\mathrm{H}_{2} \mathrm{~S}$ at room temperature (Figure $4 \mathrm{f}$, inset). The IDEs were pre-functionalized with an $\mathrm{OH}$-terminated monolayer (11-mercaptoundecanol) prior to the growth of fum-fcu-MOF. The sensing performance of the fabricated crystals towards different gases was investigated after activation of the sample under vacuum for one hour. The device showed remarkable sensitivity towards $\mathrm{H}_{2} \mathrm{~S}$ at concentrations down to $100 \mathrm{ppb}$, with a linear sensing response and an impressive LOD of $5 \mathrm{ppb}$ (Figure 4f).

In addition to high sensitivity, the sensor demonstrated excellent selectivity towards $\mathrm{H}_{2} \mathrm{~S}$ with almost negligible signals upon exposure to other gases, including $\mathrm{CH}_{4}, \mathrm{H}_{2}$ and $\mathrm{C}_{7} \mathrm{H}_{8}$ (toluene). A slight cross-sensitivity was detected towards $\mathrm{NO}_{2}$ gas molecules; however, the sensing layer showed a six-fold higher sensing response to $\mathrm{H}_{2} \mathrm{~S}$ compared to $\mathrm{NO}_{2}$ gas. This outstanding sensing performance could be attributed to the interconnected octahedral and tetrahedral cages of fum-fcu-MOF which significantly reduces the gas diffusion resistance and consequently enhances the sensing response to target gas.

The stability of sensing performance for the fum-fcu-MOF layer towards $\mathrm{H}_{2} \mathrm{~S}$ was investigated over a period of three months, exhibiting excellent stability and uniform detection levels over a range of cycles. To demonstrate the excellent stability of the fabricated sensor, the sensing performance of two other MOF sensors, namely, ZIF-8 and $\mathrm{Cu}(\mathrm{BDC}) \cdot \mathrm{xH}_{2} \mathrm{O}$ (BDC: benzenedicarboxylate), was tested for $4000 \mathrm{~s}$. These tests revealed a significant reduction in the sensing performance of these devices after only $1000 \mathrm{~s}$ (Figure $4 \mathrm{~g}$ ). This lower stability could be attributed to the degradation of the MOF structures and the formation of metal sulphide components upon prolonged $\mathrm{H}_{2} \mathrm{~S}$ exposure. In contrast, the metal clusters in the fum-fcu-MOF structure were bridged by shorter and rigid liners, prohibiting the formation of metal sulphides.

A similar device concept was applied by Wu et al. [94], where the surface of a $\mathrm{ZnO}$ based sensor was partially covered by porous ZIF-8 particles to improve the sensitivity and selectivity of sensing material towards $\mathrm{H}_{2} \mathrm{~S}$ gas molecules by providing larger surface areas (thus more active sites) and more abundant oxygen vacancies. This led to the expansion of the electron depletion region in the ambient atmosphere (Figure 5a) and resulted in better $\mathrm{H}_{2} \mathrm{~S}$ absorption and higher sensitivity upon gas exposure (Figure $5 \mathrm{~b}$ ). Since the pore dimension of ZIF-8 (3.4 $\AA$ ) is slightly smaller than the diameter of $\mathrm{H}_{2} \mathrm{~S}$ gas (3.6 $\AA$ ), the adsorbed $\mathrm{H}_{2} \mathrm{~S}$ gas molecules via active sites on the surface of ZIF-8 particles were pre-concentrated before transferring and being exposed to the $\mathrm{ZnO}$ surface. This partial coverage of $\mathrm{ZnO}$ by $\mathrm{ZIF}-8$ was preferable over fully covered $\mathrm{ZnO}$, as $\mathrm{H}_{2} \mathrm{~S}$ gas molecules could reach the surface of $\mathrm{ZnO}$ nanorods with no diffusion limitation through ZIF-8 particles. 

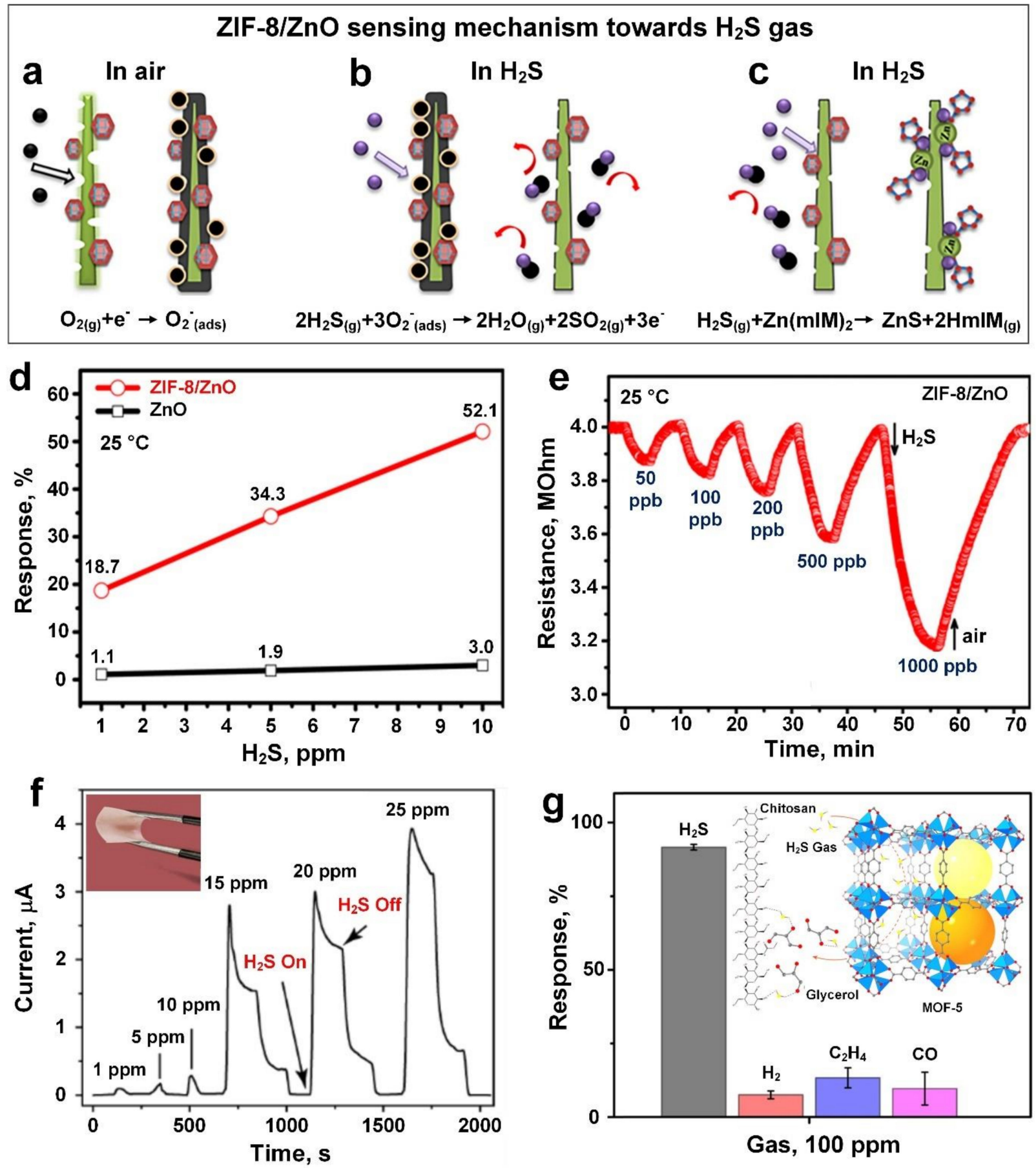

Figure 5. Schematic representation of ZIF-8/ZnO sensing mechanism towards $\mathrm{H}_{2} \mathrm{~S}$ gas: (a) the surface depletion region was expanded due to more electrons were trapped by the surface chemisorbed oxygen before the sensor was explosed to $\mathrm{H}_{2} \mathrm{~S}$ gas, the sensor exhibited a high base resistivity consequently; (b) when sensor was exposed to $\mathrm{H}_{2} \mathrm{~S}$ gas, the chemisorbed oxygen would react with $\mathrm{H}_{2} \mathrm{~S}$ molecules chemically to release the trapped electons, resulting in the reduction of depletion region and significant causing resistivity change; (c) $\mathrm{H}_{2} \mathrm{~S}$ gas might interact with $\mathrm{Zn}(\mathrm{mLm})_{2}$ transformed from ZIF-8 to form an intermediate product $(\mathrm{ZnS})$ to further enhance the sensitivity towards $\mathrm{H}_{2} \mathrm{~S}$ gas. (d) The response of $\mathrm{ZnO}$ and $\mathrm{ZIF}-8 / \mathrm{ZnO}$ toward 1,5 and $10 \mathrm{ppm}$ of $\mathrm{H}_{2} \mathrm{~S}$ gas at $25^{\circ} \mathrm{C}$. (e) The dynamic resistance curves of $\mathrm{ZIF}-8 / \mathrm{ZnO}$ against $\mathrm{H}_{2} \mathrm{~S}$ gas at ppb-level concentration. Reproduced with permission from [94] Elsevier, 2019. (f) The electrical current variation of MOF-5/CS/IL membrane against $\mathrm{H}_{2} \mathrm{~S}$ gas at different concentrations, and the flexibility demonstration of MOF-5/CS/IL membrane as inset. (g) The high cross-selectivity of MOF-5/CS/IL membrane towards $\mathrm{H}_{2} \mathrm{~S}$ compared with $\mathrm{H}_{2}, \mathrm{C}_{2} \mathrm{H}_{4}$ and $\mathrm{CO}$ gases, and the possible sensing mechanism for the outstanding $\mathrm{H}_{2} \mathrm{~S}$ gas response. Reproduced with permission from [95] American Chemical Society, 2021. 
In addition, the reaction between $\mathrm{ZIF}-8$ nanoparticles and $\mathrm{H}_{2} \mathrm{~S}$ gas results in the formation of ZnS (Figure 5c), which reduces the depletion region even further and plays a key role in the high selectivity of the developed sensing material towards $\mathrm{H}_{2} \mathrm{~S}$ over other reducing gases.

The sensing performance of the fabricated $\mathrm{ZIF}-8 / \mathrm{ZnO}$ device is presented in Figure $5 \mathrm{~d}$, demonstrating a sensing response of $18.7 \%$ and $52.1 \%$ towards $\mathrm{H}_{2} \mathrm{~S}$ gas with concentrations of 1 and 10 ppm, respectively (Figure 5d, red circles), which is correspondingly 18 and 15 times higher than for the pure $\mathrm{ZnO}$ nanorods (Figure $5 \mathrm{~d}$ black rectangles). The wellperformed ppb-level $\mathrm{H}_{2} \mathrm{~S}$ gas-sensing capability is presented in Figure 5e, starting at a very low concentration of $50 \mathrm{ppb}$. The resistance changed steadily with increasing $\mathrm{H}_{2} \mathrm{~S}$ concentration up to $1 \mathrm{ppm}$.

Despite the hydrophobic and moisture-resistive properties of ZIF-8 (demonstrating a contact angle of $138 \pm 1.5^{\circ}$ ), the sensor was still vulnerable in a humidity environment with $\mathrm{RH}$ over $50 \%$, showing an adverse impact of the moisture on the performance of $\mathrm{H}_{2} \mathrm{~S}$ gas sensing. In addition, a slow response dynamic with a long response time of $7 \mathrm{~min}$ was recorded upon exposure to $1 \mathrm{ppm}$ of $\mathrm{H}_{2} \mathrm{~S}$ gas. Further modifications are required to improve the ZIF-8 stability in a high humidity environment for achieving further humidityindependent features and enhanced response dynamics [126].

By taking advantage of the cage-bridge structure of MOF-5 $\left(\left[\mathrm{Zn}_{4} \mathrm{O}(\mathrm{BDC})_{3}\right]_{n}\right)$, Ali et al. [95] developed a high-performance gas sensor for the low concentration detection of $\mathrm{H}_{2} \mathrm{~S}$ gas molecules $(1 \mathrm{ppm})$ at room temperature. The sensing components of the device consisted of MOF-5 microparticles, blended and embedded in a conductivity-controlled chitosan organic membrane resulting in the fabrication of a flexible gas sensor (Figure $5 \mathrm{f}$, inset). The sensor demonstrated an increase in the measured current as a linear function of $\mathrm{H}_{2} \mathrm{~S}$ gas concentration with an LOD of $1 \mathrm{ppm}$ and a fast response and recovery time of $8 \mathrm{~s}$ and $30 \mathrm{~s}$, respectively (Figure 5f). This high sensitivity and fast response dynamic were attributed to the synergistic effect of promoted proton conductivity through the membrane matrix and the special cage-bridge structure of MOF-5 (Figure 5g, inset). Such synergistic sensing efforts facilitated the selectivity of MOF-5 embedded sensor towards $\mathrm{H}_{2} \mathrm{~S}$ gas with a negligible response for other reducing gases at $100 \mathrm{ppm}$ (Figure 5g). The high sensing response of $98 \%$ was maintained throughout 21 days of consecutive testing, indicating good repeatability and stability for the fabricated sensor.

The first electronic-textile $\mathrm{H}_{2} \mathrm{~S}$ gas sensor was reported by Smith et al. [96] through self-organized frameworks on textiles (SOFT) where two conductive $2 \mathrm{D}$ MOFs $\left(\mathrm{Ni}_{3} \mathrm{HHTP}_{2}\right.$ and $\mathrm{Ni}_{3} \mathrm{HITP}_{2}$, HITP: 2,3,6,7,10,11-hexaiminotriphenylene) were integrated into cotton by one-step direct solution-phase self-assembly. Using this technique, a high response of $98 \%$ and $97 \%$ was achieved towards $\mathrm{H}_{2} \mathrm{~S}$ gas in dry conditions for $\mathrm{Ni}_{3} \mathrm{HHTP}_{2}$ and $\mathrm{Ni}_{3} \mathrm{HITP}_{2}$, respectively. Interestingly, a $\sim 26 \%$ enhancement in the $\mathrm{Ni}_{3} \mathrm{HITP}_{2}$ SOFT response was observed by increasing the humidity to $18 \% \mathrm{RH}$ while $\mathrm{Ni}_{3} \mathrm{HITP}_{2}$ showed an $\sim 8 \%$ reduction in sensing performance under the same conditions. In addition to $\mathrm{H}_{2} \mathrm{~S}$ gas, the fabricated sensors exhibited high sensitivity towards other gases including nitric oxide (NO) and $\mathrm{NH}_{3}$ gas, demonstrating wide-ranging potential in the design of novel and multifunctional portable gas sensing devices.

\section{Sulphur Dioxide $\left(\mathrm{SO}_{2}\right)$}

$\mathrm{SO}_{2}$ is another toxic air pollutant, posing a serious threat to the environment and human health, with a primary one-hour acceptable limit of $75 \mathrm{ppb}$ set by the U.S. Environmental Protection Agency (EPA) [127]. A wide range of sensing materials, including metal oxide semiconductors [128-130], organic polymers [131], micro-electro-mechanicals (MEMs) [132] and carbon-based nanomaterials [133-136], are employed to develop highly sensitive and selective gas sensors for $\mathrm{SO}_{2}$ detection. However, their irreversible structural transformation upon exposure to $\mathrm{SO}_{2}$ hinders their real world application as a practical, reversible gas sensor [130]. Very recently, a series of MOF-based materials, including MOF-74 [137], DMOF-1 (double ligands: 1,4-diazabicyclo[2.2.2]octane and 
1,4-benzenedicarboxylic acid) [138] and MFM-300 (MFM: Manchester Framework Material) $[100,139]$ have been reported as promising candidates for $\mathrm{SO}_{2}$ detection at room temperature. Amongst them, indium-based MOFs, including MFM-300(In), have attracted attention as promising materials for $\mathrm{SO}_{2}$ detection due to the high $\mathrm{SO}_{2}$ sorption capacity of up to $8.28 \mathrm{mmol} \cdot \mathrm{g}^{-1}$ (at $298 \mathrm{~K}$ and $1 \mathrm{bar}$ ) and the acceptable stability of coordination compounds to highly reactive $\mathrm{SO}_{2}$ gas molecules [139].

Recently, Wang et al. [98] synthesised an amino-functionalized luminescent MOF material (MOF-5- $\mathrm{NH}_{2}$ ) on a luminescent test paper as a highly sensitive and selective $\mathrm{SO}_{2}$ gas (and its derivatives) sensor with a short response time of less than $15 \mathrm{~s}$ at room temperature. A Kipp's apparatus (Figure 6a) was used to generate the $\mathrm{SO}_{2}$ gas and control its concentration via tuning the amount of the corresponding acid. The sensing mechanism for this device was based on the interaction between MOF-5- $\mathrm{NH}_{2}$ and $\mathrm{SO}_{2}$ molecules, resulting in a change in the absorption/luminescence intensity of the sensing material under UV illumination $\left(\lambda_{\mathrm{ex}}=365 \mathrm{~nm}\right.$ ) (Figure 6b). Increasing the concentration of $\mathrm{SO}_{2}$ from 0 to $3 \mathrm{ppm}$ resulted in a significant increase in the brightness of the luminescent test papers, with an LOD-lightened concentration of $0.05 \mathrm{ppm}$, suggesting that MOF-5- $\mathrm{NH}_{2}$ is a promising material for the selective detection of low concentrations of $\mathrm{SO}_{2}$ at room temperature. In contrast to MOF-5- $\mathrm{NH}_{2}$, no change was detected in the luminescence intensity of MOF- 5 after exposure to $\mathrm{SO}_{2}$, emphasising the important role that the $-\mathrm{NH}_{2}$ group plays in the luminescent sensing of MOFs. This observation is in strong agreement with other studies reporting the utilisation of amino-functionalized materials and the selective identification of $\mathrm{SO}_{2}$ derivatives [140].
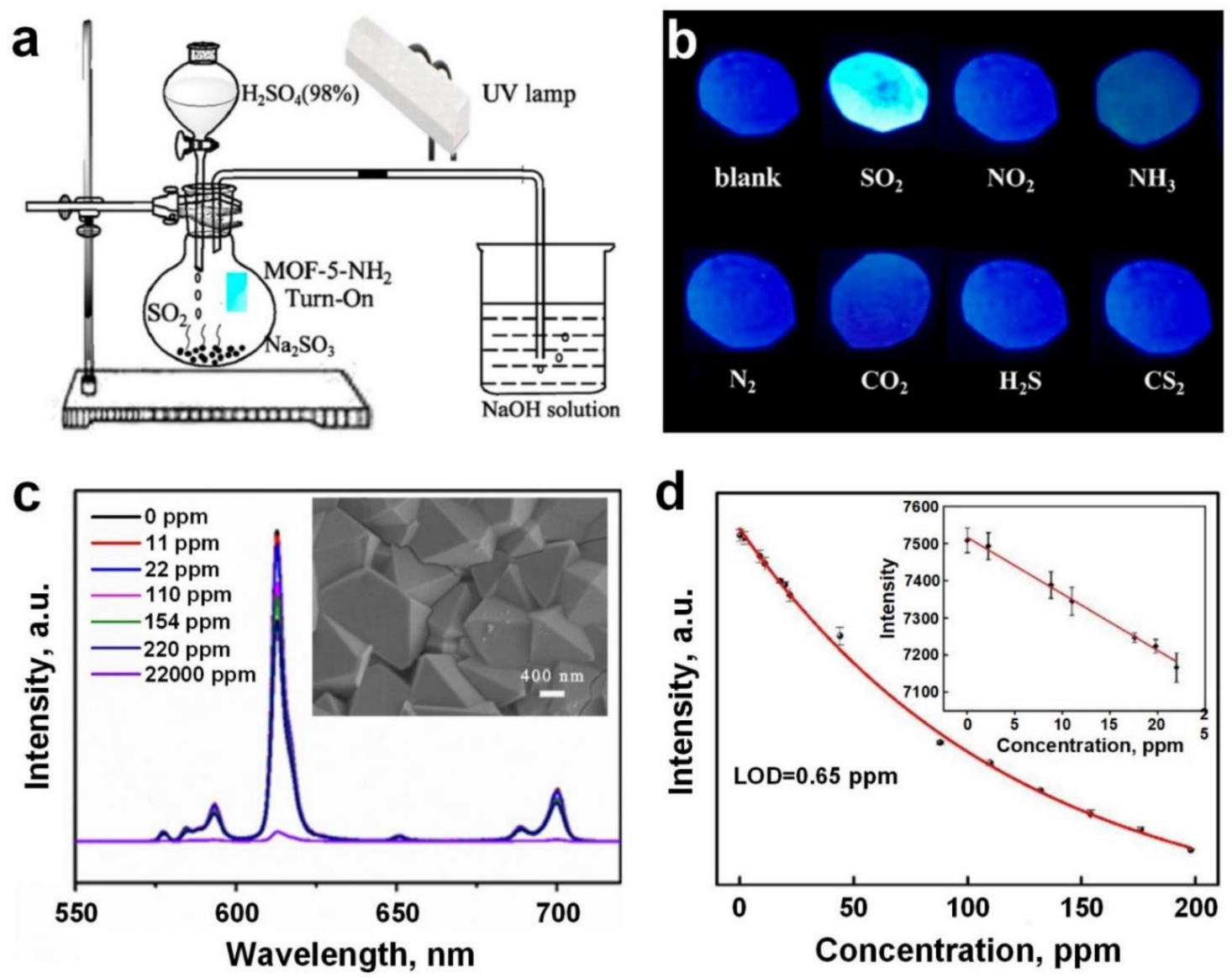

Figure 6. (a) Schematic illustration of Kipp's apparatus used for producing $\mathrm{SO}_{2}$ gas. (b) Photographs of $\mathrm{MOF}-5-\mathrm{NH}_{2}$ luminescent test papers upon exposure to different gases (2 ppm concentration) under a $365 \mathrm{~nm}$ UV lamp. Reproduced with permission from [98] American Chemical Society, 2018. (c) The emission spectra of Eu-BDC-NH ${ }_{2}$ film upon exposure to $\mathrm{SO}_{2}$ gas at different concentrations, and the SEM image of Eu-BDC-NH${ }_{2}$ film (Inset). (d) The relationship of fluorescence 
intensity versus $\mathrm{SO}_{2}$ gas for a range of concentrations; the inset displays a linear correlation within a low $\mathrm{SO}_{2}$ gas concentration range (0-25 ppm). Reproduced with permission from [99] Elsevier, 2018.

In a similar approach, Zhang et al. [99] devised a novel technique of "in situ secondary growth" to readily synthesise Eu-BDC- $\mathrm{NH}_{2} \mathrm{MOF}$ (amino-functionalized) on glass substrates using solvothermally fabricated $\mathrm{UiO}-66-\mathrm{NH}_{2}$ (resulting from the combination of zirconium salt and 2-aminoterephthalic acid $\left(\mathrm{H}_{2} \mathrm{BDC}-\mathrm{NH}_{2}\right)$; $\mathrm{UiO}$ is short for the University of Oslo) as the seed layer for the optical detection of $\mathrm{SO}_{2}$. As the structure and molecular content of UiO-66- $\mathrm{NH}_{2}$ crystals are well-matched to Eu-BDC- $\mathrm{NH}_{2}$, tightly coherent crackfree Eu-BDC- $\mathrm{NH}_{2}$ films with controllable grain size and film thickness were synthesised (Figure $6 c$, inset). The fabricated Eu-BDC- $\mathrm{NH}_{2}$ film was found to exhibit distinctively characteristic $\mathrm{Eu}^{3+}$ emissions at 594, 615 and $699 \mathrm{~nm}$ under $370 \mathrm{~nm}$ excitation within $\mathrm{N}_{2}$ due to band transition $\left({ }^{5} \mathrm{D}_{0} \rightarrow{ }^{7} \mathrm{~F}_{\mathrm{J}} \mathrm{J}=1,2,4\right)$. However, these fingerprint emissions could be significantly suppressed by increasing $\mathrm{SO}_{2}$ gas concentrations, as depicted in Figure 6c; all emission intensities decreased significantly as $\mathrm{SO}_{2}$ concentrations were increased from 0 to $220 \mathrm{ppm}$. The overall emissions were further quenched with a sharp increase in the $\mathrm{SO}_{2}$ concentration to $22,000 \mathrm{ppm}$, demonstrating an exponential drop in the luminescence intensity of the sensing materials (Figure $6 \mathrm{~d}$ ). However, at low $\mathrm{SO}_{2}$ gas concentrations $(\leq 25 \mathrm{ppm}$ ), a good linear correlation between the two variables was observed (Figure $7 \mathrm{~d}$, inset). Meanwhile, the LOD was calculated to be $0.65 \mathrm{ppm}$, which is significantly lower than the Occupational Safety and Health Administration (OSHA) warning value for $\mathrm{SO}_{2}$ gas [116]. 

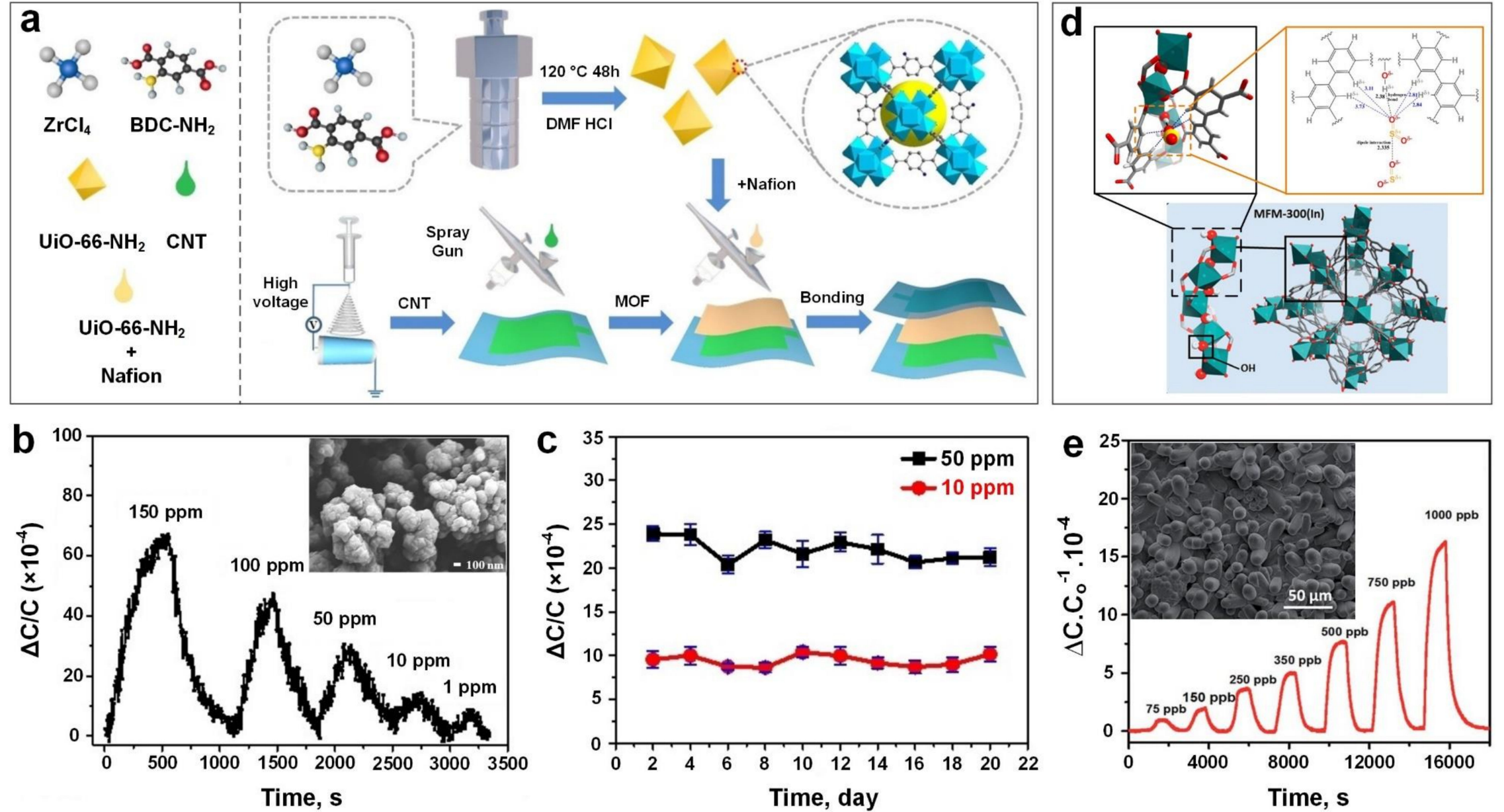

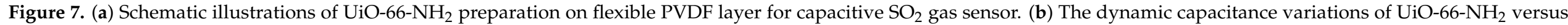

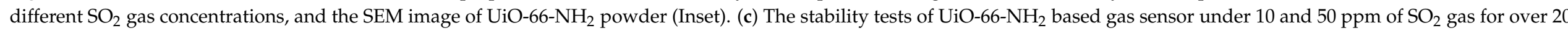

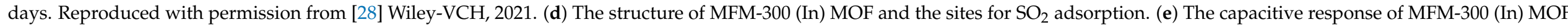
against varied $\mathrm{SO}_{2}$ gas concentrations, and the SEM image of MFM-300 (In) MOF thin film as inset. Reproduced with permission from [100] The Royal Society of Chemistry, 2018. 
Very recently, Zhang et al. [28] developed a capacitive-based sensing material using a relatively simple fabrication process (Figure 7a) for the real-time monitoring of $\mathrm{SO}_{2}$ gas molecules at room temperature. The sensing technology was introduced by using polyvinylidenefluoride (PVDF) nanofibers (with a diameter of 300-400 $\mathrm{nm}$ ) coated with a thin layer of $\mathrm{UiO}-66-\mathrm{NH}_{2} \mathrm{MOF}$ (200 nm in size) (Figure $7 \mathrm{~b}$, inset) as a dielectric layer and carbon nanotubes (CNTs) as an electrode. The fabricated sensing material demonstrated a high sensitivity towards $\mathrm{SO}_{2}$ in a large ppm range from $1 \mathrm{ppm}$ to $150 \mathrm{ppm}$ (Figure $7 \mathrm{~b}$ ), high stability (over a testing period of 20 days) (Figure 7c) and excellent bending flexibility (2000 bending cycles), with a short response time of $185 \mathrm{~s}$ for detecting a low concentration of $\mathrm{SO}_{2}$ gas. The sensing mechanism was based on the change in the dielectric constant of UiO-66- $\mathrm{NH}_{2} \mathrm{MOF}$ layer due to the physical adsorption of $\mathrm{SO}_{2}$ gas molecules in the MOF pores and voids. Interestingly, it demonstrated a faster response dynamic (both response and recovery time) after bending (compared to an unbended sample), which could be attributed to the shortened distance between the electrode and dielectric layer, resulting in a shorter transfer path for gas molecules to reach the dialectic layer, and consequently faster response dynamics.

Using a simple solvothermal technique, Chernikova et al. [100] deposited a layer of MFM-300 (a 3-periodic open framework composing of $\mathrm{InO}_{4}(\mathrm{OH})_{2}$ octahedral chains bridged by tetradentate ligands (biphenyl-3,3',5,5'-tetracarboxylic acid)) (Figure 7d), on a silicon wafer featuring a capacitive interdigitated electrode functionalized with 11-Mercapto1-undecanol, for the low concentration detection of $\mathrm{SO}_{2}$ gas molecules. The sensing performance of the proposed porous nanostructured layer (Figure 7e, inset) was investigated by monitoring the changes in capacitance upon exposure to a selection of different gas molecules including $\mathrm{SO}_{2}, \mathrm{CH}_{4}, \mathrm{CO}_{2}, \mathrm{NO}_{2}$ and $\mathrm{H}_{2}$. The results showed outstanding detection sensitivity to $\mathrm{SO}_{2}$ down to $75 \mathrm{ppb}$ (Figure 6e) with a lower detection limit of $5 \mathrm{ppb}$ and excellent selectivity towards $\mathrm{SO}_{2}$ compared to other gases with slight cross-selectivity with $\mathrm{CO}_{2}$ (four times less sensitive compared to $\mathrm{SO}_{2}$ ).

The sensing mechanism was based on the interaction between $\mathrm{SO}_{2}$ molecules and the exposed hydrogen centres from free hydroxyl (OH-) groups on the surface of MFM-300 (Figure 7d), leading to the formation of hydrogen bonds between $\mathrm{SO}_{2}$ and the sensing materials [100]. Similarly, the neighbouring C-H groups from the benzene ring of the ligand can contribute to $\mathrm{SO}_{2}$ detection by providing further adsorption sites on the surface (Figure 7d), resulting in excellent sensitivity and selectivity towards $\mathrm{SO}_{2}$. Interestingly, the adsorbed $\mathrm{SO}_{2}$ molecules on the surface can interact with each other through analyte-analyte interaction (dipoles), leading to a higher capacitance change in the sensors.

The effect of humidity level on sensing performance of the active film upon $\mathrm{SO}_{2}$ exposure was investigated at 1000 and $350 \mathrm{ppb}$ gas concentrations, and at relative humidity (RH) from $5 \%$ to $85 \%$. In contrast to conventional gas sensors including metal oxide semiconductors, the sensing performance of the MFM-300-based gas sensor was enhanced significantly by increasing the $\mathrm{RH}$ up to $85 \%$. This higher sensing response was attributed to the formation of additional hydrogen bonding between $\mathrm{SO}_{2}$ gas molecules and adsorbed water molecules on the MOF's surface, resulting in a higher capacitance change $[107,141]$. In addition, the MFM-300 layer demonstrated a higher sensing performance at lower operating temperature with an optimal operating temperature of $22^{\circ} \mathrm{C}$, making it a promising material for highly sensitive, room temperature nanosensors for the ultra-low concentration detection of $\mathrm{SO}_{2}$ gas molecules. This higher sensitivity could be attributed to a lower molecule diffusion rate and consequently, a higher analyte adsorption rate at a lower temperature [100].

Although the UiO-66( $\mathrm{Zr}$ ) family of MOFs is unreactive by nature towards acid gases such $\mathrm{SO}_{2}, \mathrm{CO}_{2}$ and $\mathrm{NO}_{2}$, functionalising the surface of UiO-66 with an amine moiety can convert it into a chemoresistive acidic gas sensor [101]. The $\mathrm{NH}_{2}-\mathrm{OH}-\mathrm{UiO}-66$ exhibited an attractive response of $11.4 \pm 2.2 \%$ for $10 \mathrm{ppm} \mathrm{SO}_{2}$ with a fast response and decay time of $26.8 \mathrm{~s}$ and $46.1 \mathrm{~s}$, respectively. It was shown that the bandgap of pelletized $\mathrm{NH}_{2-}$ 
$\mathrm{OH}-\mathrm{UiO}-66$ narrowed down to $2.75 \mathrm{eV}$ compared to the $3.05 \mathrm{eV}$ of Uio-66, indicating an increased charge density at the lowest unoccupied crystalline orbitals (LUCO). Meanwhile, a suggested electron-hopping transport was observed with a decrease of resistance at elevated temperatures. The transformations between a semiconductor and insulator for $\mathrm{NH}_{2}-\mathrm{OH}-\mathrm{UiO}-66$ make it an intriguing candidate for $\mathrm{SO}_{2}$ gas sensing chemoresistively at low concentrations (observed response of 3.2\% with concentrations down to $1 \mathrm{ppm}$ ). Additionally, $\mathrm{NH}_{2}-\mathrm{UiO}-66$ outperformed the $\mathrm{OH}-\mathrm{UiO}-66(\mathrm{Zr})$ and $\mathrm{NH}_{2}-\mathrm{OH}-\mathrm{UiO}-66$ with approximate 5-fold and 3-fold enhanced responses $\left(4.1 \%\right.$ and $7.1 \%$ for $\mathrm{OH}-\mathrm{UiO}-66$ and $\mathrm{NH}_{2}-$ $\mathrm{OH}-\mathrm{UiO}-66$, respectively), highlighting the importance of carefully selecting an appropriate linker for sensing a specific target gas. However, the elevated operating temperature of $150{ }^{\circ} \mathrm{C}$ could hinder their applications in practice where room temperature or near room temperature operation is needed.

In another approach, Ingle et al. [102] fabricated a flexible $\mathrm{SO}_{2}$ gas sensor based on a crystalline nickel (II) benzenetricarboxylate metal-organic framework (Ni-MOF). In this device, the Ni-MOF composited with hydroxyl group $(-\mathrm{OH})$ activated single-wall carbon nanotubes (SWNTs) and multi-wall carbon nanotubes (MWNTs), namely, Ni-MOF/-OHSWNTs and Ni-MOF/-OH-MWNTs. Both CNT-modified Ni-MOF microdevices exhibited a discriminating response upon $\mathrm{SO}_{2}$ exposure, which was contributed by the highly sensitive surface network of CNTs [142] providing favourable conditions for electron transportation [143]. The Ni-MOF/-OH-SWNTs sensor showed higher $\mathrm{SO}_{2}$ sensing performance compared to the Ni-MOF/-OH-MWNTs at different $\mathrm{SO}_{2}$ concentrations. This was due to holes being the majority charge careers in Ni-MOF/-OH-SWNTs [144] resulting in better interaction with electron donor analytes such as $\mathrm{SO}_{2}$ gas molecules. However, a slow recovery speed was observed which could be attributed to the honeycomb structure of the CNTs as this plays a significant role in holding the gas molecules on the sensor's surface for a longer time [142,145] prolonging the recovery dynamics of the device. A high sensing selectivity towards $\mathrm{SO}_{2}$ molecules was also achieved using the MOF/CNT composite material compared to other gases, including $\mathrm{NO}_{2}, \mathrm{NH}_{3}$ and $\mathrm{CO}$ gases, at relatively high concentrations ( $\geq 10 \mathrm{ppm})$.

\section{Carbon Dioxide $\left(\mathrm{CO}_{2}\right)$}

Despite the modest greenhouse effect of $\mathrm{CO}_{2}$ compared to methane $\left(\mathrm{CH}_{4}\right)$ and nitrous oxide $\left(\mathrm{N}_{2} \mathrm{O}\right)$, which possess 25 and 298 times more global warming potential (GWP) than $\mathrm{CO}_{2}$, respectively $[146,147], \mathrm{CO}_{2}$ is widely understood to be the major driver of climate change due to its dominant concentrations in the atmosphere $(0.04 \mathrm{vol} \%)$ when compared to other types of greenhouse gas [148]. Sustained exposure to $\mathrm{CO}_{2}$ gas indoors can cause inflammation and oxidative stress at a modest concentration level of 1000 ppm [149,150]. Thus, ongoing monitoring of indoor and outdoor $\mathrm{CO}_{2}$ gas levels with reliable, portable and cost-effective sensing systems is highly desired in many industrial sectors.

Recently, a novel sensing mechanism was introduced to leverage small molecules by extremely small differences in the refractive indices (RI) of MOF nanofilms as a function of analyte adsorption within a MOF layer. This allows for the detection of chemical compounds at the molecular level via slight distinctions in refractive index (RI) through utilization of an optical-fiber-waveguide framework (Figure 8a(i)). Using a simple solutionbased technique, Kim et al. [103] synthesised a uniform, dense and continuous layer of ZIF-8 around an etched fiber optical sensor (Figure 8a(ii,iii)) for low concentration detection of $\mathrm{CO}_{2}$ gas molecules at room temperature. The transmittance of the ZIF-8 coated optical fibre at the wavelength of $242 \mathrm{~nm}$ decreased by a factor of 2 from $100 \%$ to $50 \%$ by increasing the concentration of $\mathrm{CO}_{2}$ gas molecules from zero to $100 \%$ (Figure $8 \mathrm{~b}$ ), indicating a linear relationship between the sensing response and the concentration of $\mathrm{CO}_{2}$ gas (Figure $8 \mathrm{~b}$, inset). The sensing mechanism is based on a shift in the RI of the ZIF-8 layer due to the adsorption of $\mathrm{CO}_{2}$ gas molecules into the MOF apertures. According to the Lorenz-Lorentz law, the density of ZIF-8 film increases when $\mathrm{CO}_{2}$ gas molecules are adsorbed on the surface, resulting in a change in the RI of the MOF layer. This RI change in 
the MOF layer is proportional to the number of $\mathrm{CO}_{2}$ molecules adsorbed on the surface. Hence, the closer the RI of the MOF layer is to the RI of the fibre, the more light propagates from the fibre optic into the MOF film, resulting in lower transmittance at the wavelength of $242 \mathrm{~nm}$ [103].

a
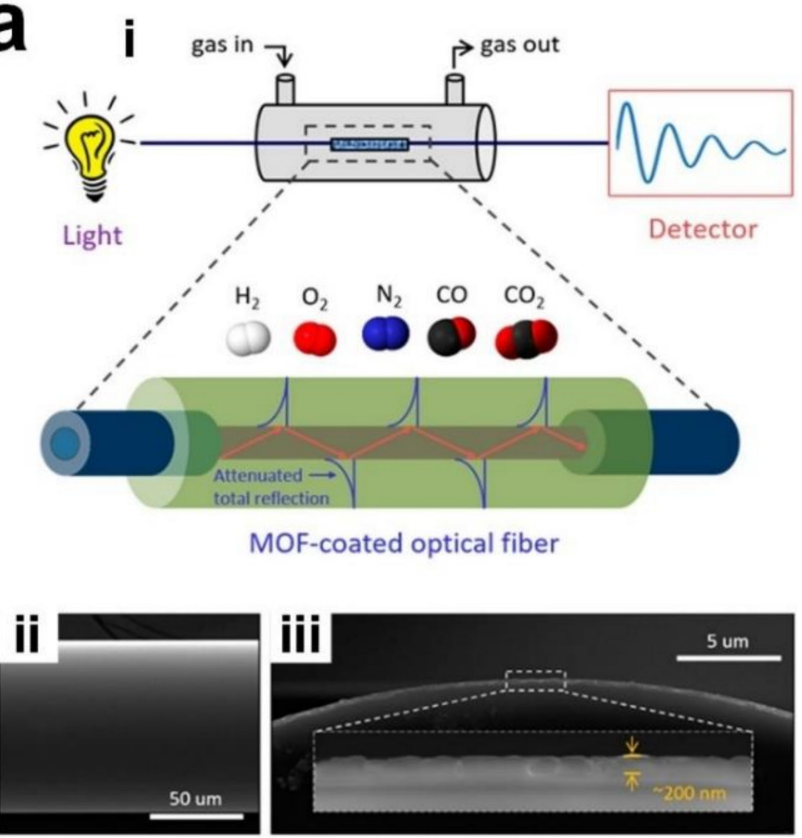

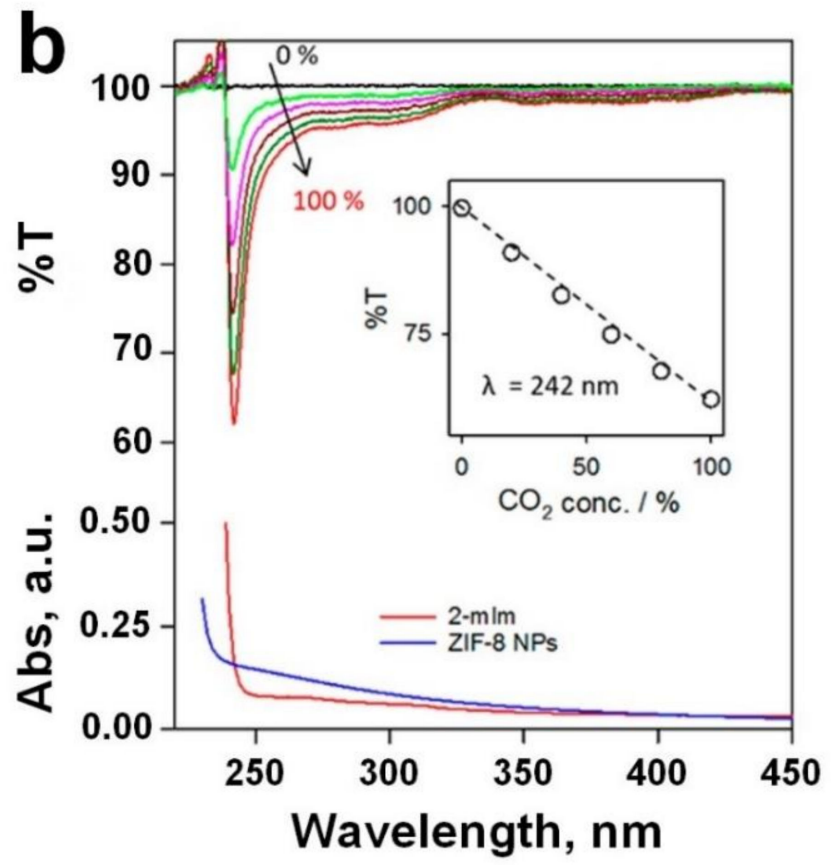

C

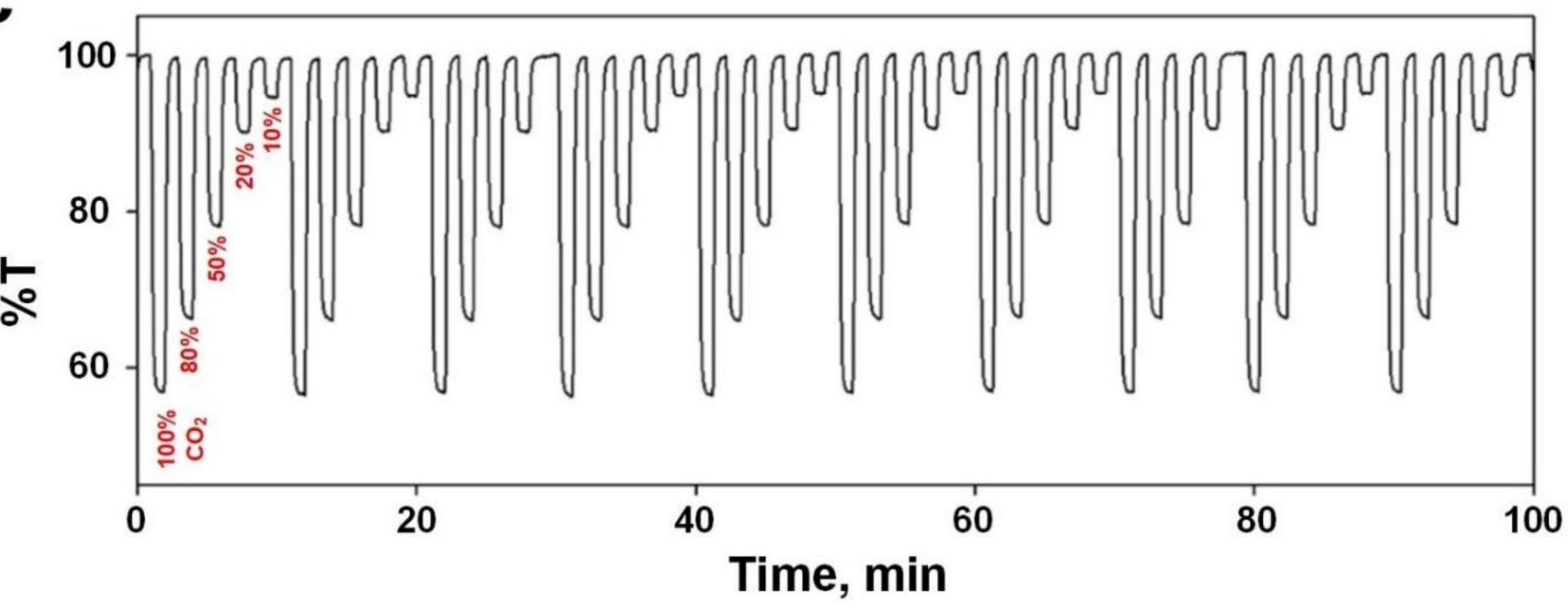

Figure 8. (a(i)) Graphic representation of the gas detection system using MOF-coated optical fiber. FESEM images of top (a(ii)) and side (a(iii)) views of optical fiber covered by $200 \mathrm{~nm}$ thick ZIF-8. (b) The transmittance spectra of $350 \mathrm{~nm}$ thick ZIF-8 coated optical fiber against varied $\mathrm{CO}_{2}$ levels, and the absorbance spectra of 2-mIm and ZIF- 8 . A linearity of \%T $(\lambda=242 \mathrm{~nm})$ and $\mathrm{CO}_{2}$ concentrations was plotted as inset. (c) Ten cyclic dynamic responses of $200 \mathrm{~nm}$ thick ZIF- 8 coated optical fiber under different $\mathrm{CO}_{2}$ concentrations. Reproduced with permission from [103] American Chemical Society, 2018.

This lower transmittance was mainly due to a significant absorbance wavelength $(\lambda=242 \mathrm{~nm})$ induced by the 2-methylimidazole linker within the ZIF-8 layer, as indicated by the observed similarity with the maximum absorbance wavelength obtained for the free 2-methylimidazole linker in the diluted fluid (Figure 8b). At wavelengths over $250 \mathrm{~nm}$, the changes in transmittances are negligible due to the weak 2-methylimidazole absorption band trail at longer wavelengths (Figure 8b) [103]. This sensing technology demonstrated a remarkably fast response and recovery time of $14 \mathrm{~s}$ and $9 \mathrm{~s}$, respectively, for $200 \mathrm{~nm}$ 
thick ZIF-8 film. However, the response and recovery times increased to 84 and $24 \mathrm{~s}$, respectively, by increasing the ZIF-8 film thickness to $530 \mathrm{~nm}$. This slower response dynamic could be attributed to the long-range diffusion rate of gas transferring through the ZIF-8 crystallites toward the interior of the film. In addition, excellent repeatability (Figure $8 \mathrm{c}$ ) and high selectivity towards $\mathrm{CO}_{2}$ gas molecules were observed compared to other gases with relatively small molecule sizes, including $\mathrm{H}_{2}, \mathrm{~N}_{2}, \mathrm{O}_{2}$, and $\mathrm{CO}$.

Using an in situ solvothermal technique, Yuan et al. [9] fabricated a tailorable capacitive sensor for selective detection of benzene vapour and $\mathrm{CO}_{2}$ gas molecules at room temperature. The sensor was made of Mg-MOF-74 crystallites grown on a silicon nitride $\left(\mathrm{Si}_{3} \mathrm{~N}_{4}\right)$ substrate featuring platinum (Pt) IDEs (Figure 9a,b). By changing the metal ion $(\mathrm{Mg})$ to linker (2,5-dioxido-1,4-benzenedicarboxylate (DOBDC)) ratio ( $\mathrm{k}$ ) for the MOF growth, a thick $(7 \mu \mathrm{m})$ and compact film morphology with intergrown hexagonal crystallites (Figure 9c,d) was observed for $k>3$, compared to isolated hexagonal bunches with free space on the substrate for $\kappa<2$. This change in the morphology is attributed to the competition between the simultaneous homogeneous and heterogeneous nucleation and growth of the Mg-MOF-74 films. The homogeneous (in solution) nucleation was dominant at a lower $\mathrm{k}$ where a higher concentration of ligand led to precursor consumption, powder formation and, consequently, growth restriction, and resultant formation of additional voids on the surface. In contrast, the nucleation was limited at a higher $k$ where heterogenous (on surface) growth was promoted, resulting in the formation of highly intergrown crystallites forming a dense and compact layer (Figure 9d).

The sensing performance of the MOF film was investigated by measuring the capacitance change upon exposure to different gases including methane, benzene and $\mathrm{CO}_{2}$, resulting in an outstanding sensing response of $\sim 1$ towards 200 ppm $\mathrm{CO}_{2}$ vapour (Figure 9e). This response is attributed to the interaction between unsaturated open metal sites of the Mg-MOF-74 crystallites (as an electron acceptor) and adsorbed $\mathrm{CO}_{2}$ molecules acting as electron donors. A positive linear response was reported upon increasing the $\mathrm{CO}_{2}$ gas concentration from 200 to $5000 \mathrm{ppm}$ and attributed to the linear change in the dielectric constant of the Mg-MOF-74 layer over the gas adsorption on the surface (Figure 9e, inset). However, no obvious response was detected for other gases, including methane, at similar concentrations. Post-synthesis modification of these MOF layers with ethylenediamine slightly increased their sensitivity towards $\mathrm{CO}_{2}$. However, further investigations are required to reveal the key factors in the sensing performance of Mg-MOF-74 crystallites and their surface-analyte interaction with different gas molecules.

Inspired by the Guest@MOF concept which combines MOFs and guest molecules to prompt the conductivity of MOF [151], Strauss et al. [152] designed a chemoresistive gas sensor based on one-dimensional Co-MOF-74-TTF (Figure 9f, inset) materials. This was achieved by infiltration of Co-MOF-74 (with Co as the metallic centre linked by 2,5-dioxido-1,4-benzenedicarboxylate ligands) powder with the organic semiconductor tetrathiafulvalene (TTF) [152]. As presented in Figure 9f, a significant increase in the $\mathrm{CO}_{2}$ uptake (up to $100 \mathrm{cc} \cdot \mathrm{g}^{-1}$ ) was observed when the $\mathrm{CO}_{2}$ pressure inside the cell was increased stepwise up to 1000 mbar. In contrast, the $\mathrm{CO}_{2}$ uptake only increased up to 18 $\mathrm{cc} \cdot \mathrm{g}^{-1}$ for Co-MOF-74-TTF after increasing the $\mathrm{CO}_{2}$ pressure to $1000 \mathrm{mbar}$. This lower $\mathrm{CO}_{2}$ uptake could be attributed to the blockage of pore volumes in Co-MOF-74-TTF. In fact, the amount of adsorbed $\mathrm{CO}_{2}$ was drastically reduced in Co-MOF-74-TTF because of the TTF molecules infiltrated into the pores (i.e., successful infiltration). 

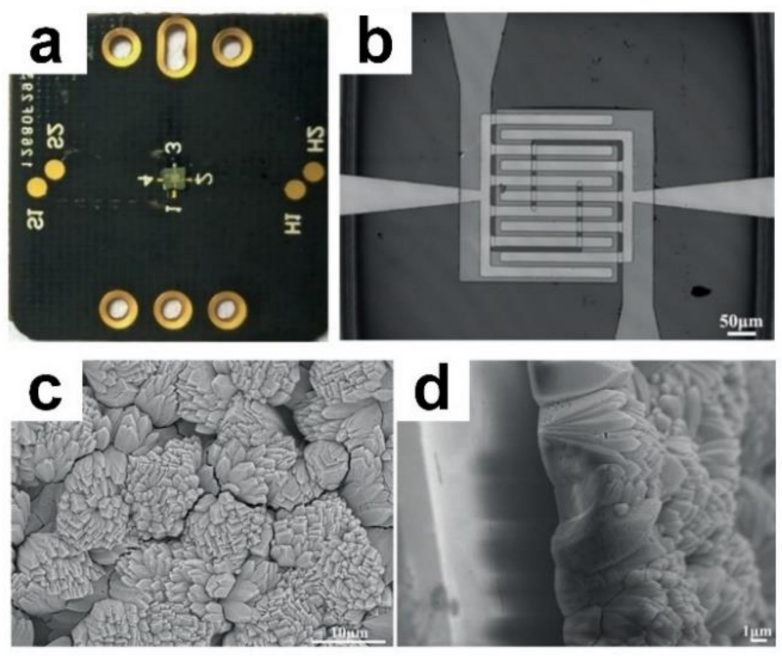

$f$
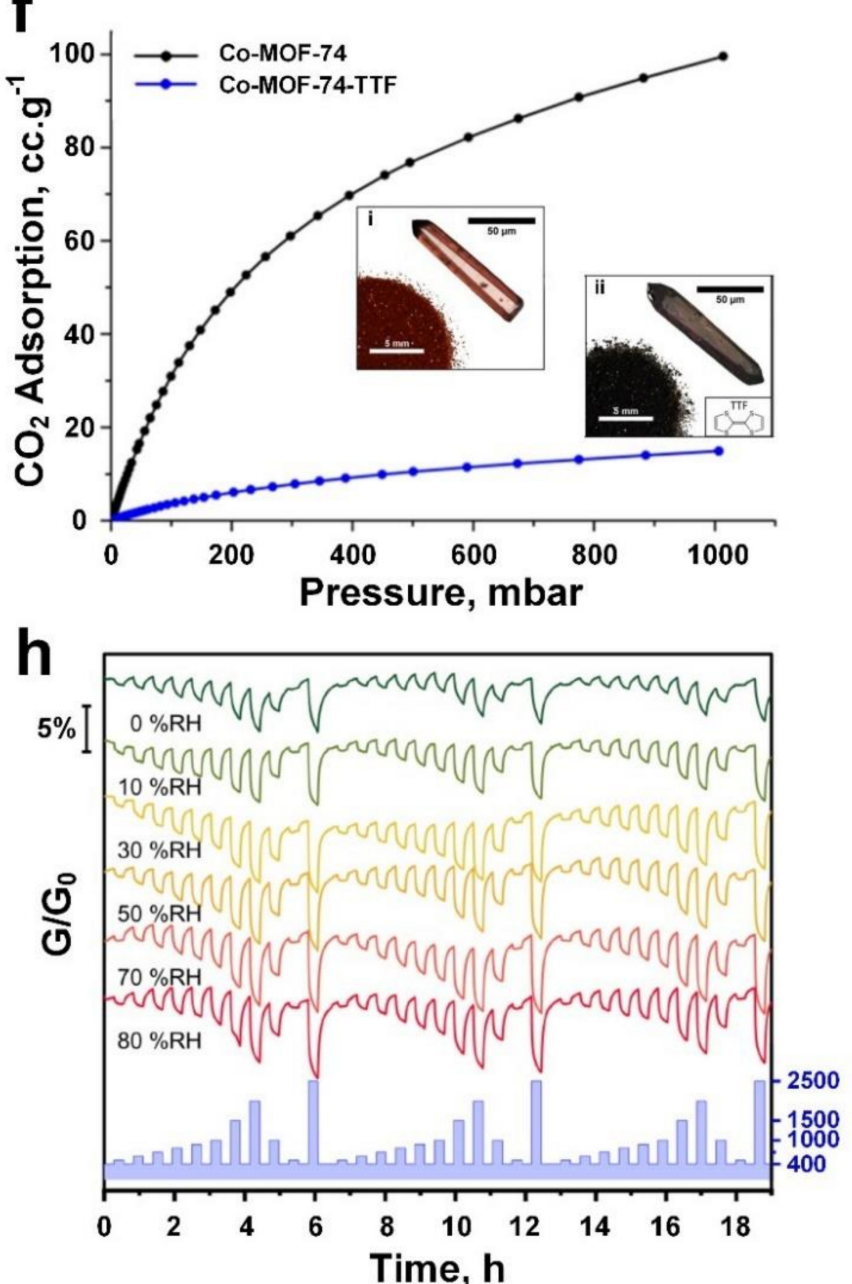
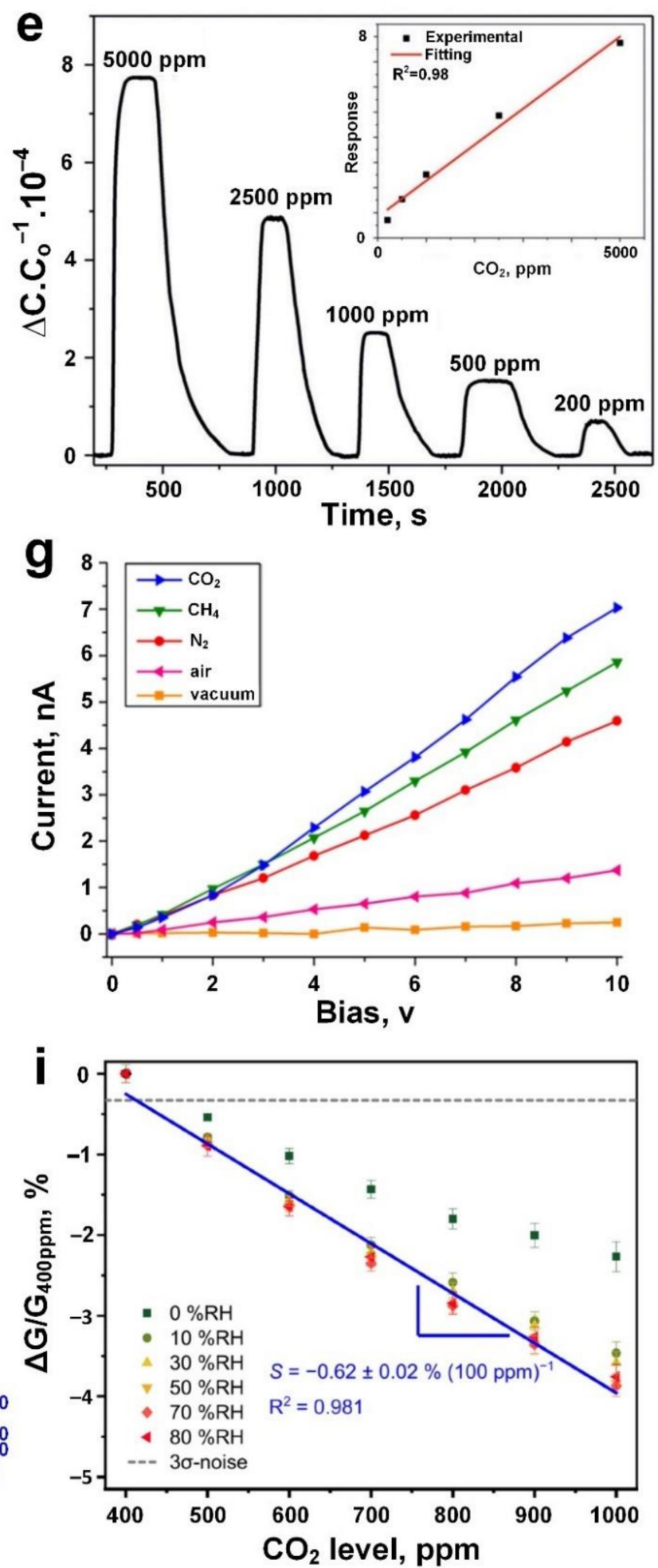

Figure 9. (a) Photograph of Mg-MOF-74 film-based $\mathrm{CO}_{2}$ capacitive gas sensor. (b) Optical image of Pt IDEs. (c,d) SEM images of the top (c) and side (d) views of the as-grown Mg-MOF-74 film on IDEs. (e) The dynamic response of ethylenediamine-modified Mg-MOF-74 film against $\mathrm{CO}_{2}$ at different concentrations, the response varied proportionally to the $\mathrm{CO}_{2}$ concentration (inset). Reproduced with permission from [9] Wiley-VCH, 2019. (f) $\mathrm{CO}_{2}$ adsorption isotherms of Co-MOF-74 (i) and Co-MOF-74-TTF (ii). (g) The $I-V$ curves of Co-MOF-74-TTF under $\mathrm{CO}_{2}$ and other atmospheric conditions. Reproduced with permission from [152] American Chemical Society, 2019. (h) The normalized dynamic response curves and, (i) response versus $\mathrm{CO}_{2}$ gas at different concentrations for various humidity scenarios $(0-80 \% \mathrm{RH})$. Reproduced with permission from [104] American Chemical Society, 2019. 
To investigate the gas-sensing capability of Co-MOF-74-TTF, the $I-V$ characteristics of the sensing material was measured after $24 \mathrm{~h}$ under vacuum, air, $\mathrm{N}_{2}, \mathrm{CH}_{4}$, and $\mathrm{CO}_{2}$ atmospheres, respectively, at an applied voltage up to $10 \mathrm{~V}$. The material demonstrated a higher sensing performance towards $\mathrm{CO}_{2}$ gas molecules (current of $7 \mathrm{nA}$ ) compared to other gases including $\mathrm{CH}_{4}$ (current of $6 \mathrm{nA}$ ) and $\mathrm{N}_{2}$ (current of $4.5 \mathrm{nA}$ ) at $10 \mathrm{~V}$ (Figure 9g). This higher sensing performance could be attributed to the strong interaction between open-metal Co-centres (acting as the Lewis acid) of $\mathrm{MOF}$ and $\mathrm{CO}_{2}$ gas molecules (acting as the Lewis base/electron donor) resulting in the highest conductivity of the fabricated sensing material upon exposure to $\mathrm{CO}_{2}$ gas (Figure $9 \mathrm{~g}$ ), while a smaller increase in the conductivity was observed for weaker gas-MOF interactions $\left(\mathrm{CO}_{2}>\mathrm{CH}_{4}>\mathrm{N}_{2}\right)$. In fact, the permanent dipole moment, which is present in the cobalt atoms, could induce the polarization of molecules such as $\mathrm{CH}_{4}$, resulting in the lower affinity of Co-MOF-74 toward $\mathrm{CH}_{4}$ compared to $\mathrm{CO}_{2}$ [153]. In addition, a significantly lower interaction was expected for $\mathrm{N}_{2}$, as an inert gas, resulting in a lower sensing response towards $\mathrm{N}_{2}$ gas molecules. Further investigation is required to resolve the poor selectivity and slow response dynamics (>500 $\mathrm{min}$ ) of these Co-MOF-74-TTF for their real-world application as $\mathrm{CO}_{2}$ gas sensors [152].

In another approach, Stassen et al. [104] reported the fabrication of an ambient $\mathrm{CO}_{2}$ chemoresistor platform based on nanoporous, electrically conducting 2D MOFs deposited on $\mathrm{Al}_{2} \mathrm{O}_{3}$ substrates featuring IDEs. The normalized response dynamics of the fabricated sensing MOFs $\left.\left(\mathrm{Cu}_{3} \text { (hexaiminobenzene }\right)_{2}, \mathrm{Cu}_{3}(\mathrm{HIB})_{2}\right)$ at different $\mathrm{CO}_{2}$ concentrations (400-2500 ppm) demonstrated a highly repeatable and robust operation over 7 days of continuous experimentation and remarkable humidity-independence across a wide range of relative humidity (10-80\% RH) (Figure $9 \mathrm{~h}$ ). Figure $9 \mathrm{i}$ shows the quantitative responses of the sensing material upon exposure to $\mathrm{CO}_{2}$ gas molecules across a concentration range of 400 to 1000 ppm, demonstrating a linear response-concentration relationship and an average response of $0.62 \% / 100$ ppm over the broad range of ambient humidity (10-80\% $\mathrm{RH})$. This strong $\mathrm{RH}$-independency of the $\mathrm{Cu}_{3}(\mathrm{HIB})_{2}$ senor towards $\mathrm{CO}_{2}$ gas molecules could be attributed to the autogenously generated hydrated adsorption sites and a charge trap mechanism of $\mathrm{Cu}_{3}(\mathrm{HIB})_{2}$ resulting in such intriguing $\mathrm{CO}_{2}$ sensing performance at high $\mathrm{RH}$, outperforming other amine-rich based $\mathrm{CO}_{2}$ sensors including polyethylenimine (PEI) [154] and ZIF-8 [155-157]. This indicates the great potential of $\mathrm{Cu}_{3}(\mathrm{HIB})_{2}$-based MOFs as remarkably stable sensing materials for real-world applications in a highly humid environment.

\section{Ammonia $\left(\mathrm{NH}_{3}\right)$}

Ammonia is one of the most important gases present in human activities, especially in relation to its use in agriculture, where nitrogenous fertilizers are extensively used. It is a corrosive and flammable gas with a pungent smell and an odour threshold range of 5-50 ppm. Exposure to a large quantity of $\mathrm{NH}_{3}$ (concentrations greater than $300 \mathrm{ppm}$ ) can cause burns to the eyes and skin and can damage the respiratory system [158]. In addition, $\mathrm{NH}_{3}$ is a natural product produced in the human body by various metabolic activities and is a promising breath biomarker for the well-being of patients with kidney and liver diseases $[159,160]$. Thus, the development of a non-invasive, flexible, reliable, robust and fast $\mathrm{NH}_{3}$ gas sensors operating at a low temperature is of great interest.

A luminescent quantitative-based sensor for $\mathrm{NH}_{3}$ gas detection fabricated by in situ

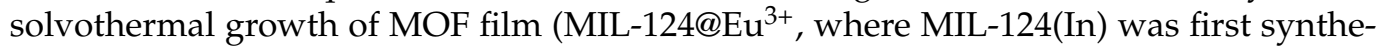
sised by mixture of $\mathrm{InCl}_{3}$ and 1,2,4-benzenetricarboxylic acid, followed by immersion into $\mathrm{Eu}^{3+}$ solution for preparation of the final product) on a porous $\alpha-\mathrm{Al}_{2} \mathrm{O}_{3}$ substrate [106]. This sensor demonstrated an outstanding sensing threshold of $26.2 \mathrm{ppm}$, which is significantly lower than the OSHA-specified health alert line of $50 \mathrm{ppm}$. The sensing mechanism was based on the partial coordination of carboxylates on the surface of MIL-124@Eu ${ }^{3+}$, leaving free $-\mathrm{COOH}$ to serve as active sites for $\mathrm{NH}_{3}$ interaction to form $-\mathrm{COONH}_{4}$. The formation of $-\mathrm{COONH}_{4}$ changes the energy transfer process between ligand and $\mathrm{Eu}^{3+}$ ions, 
leading to the quenching effect of luminescence emission of MIL-124@Eu $\mathrm{Eu}^{3+}$ film upon exposure to $\mathrm{NH}_{3}$ gas molecules.

In chemoresistors, using a rapid $(<16 \mathrm{~min})$ interfacial self-assembly method (Figure 10a), Chen et al. [108] synthesised a centimetre-sized conductive MOF film (copper benzenehexathiol, $\mathrm{Cu}$-BHT) for highly sensitive and selective detection of $\mathrm{NH}_{3}$ gas molecules at room temperature. Due to the rapid interaction between $\mathrm{Cu}^{2+}$ and $\mathrm{BHT}$ ligands usingsuch as in situ synthesis technique (Figure 10b), the Cu-BHT film was formed at the interface between $\mathrm{Cu}\left(\mathrm{NO}_{3}\right)_{2}$ aqueous solution and $\mathrm{BHT}$ organic solution within $5 \mathrm{~s}$. A continuous and uniform $\mathrm{Cu}$-BHT film was then prepared by spinning the solution off at high speed. The film thickness could be controlled by tuning the reaction time, resulting in more coordination reactions, and consequently thicker film for an extended reaction time. Figure 10b shows the crystal structure of $\mathrm{Cu}-\mathrm{BHT}$, where $\mathrm{Cu}$ ions are coordinated by BHT ligands to form a 2D kagome lattice structure with an interval distance of $3.38 \AA$. 

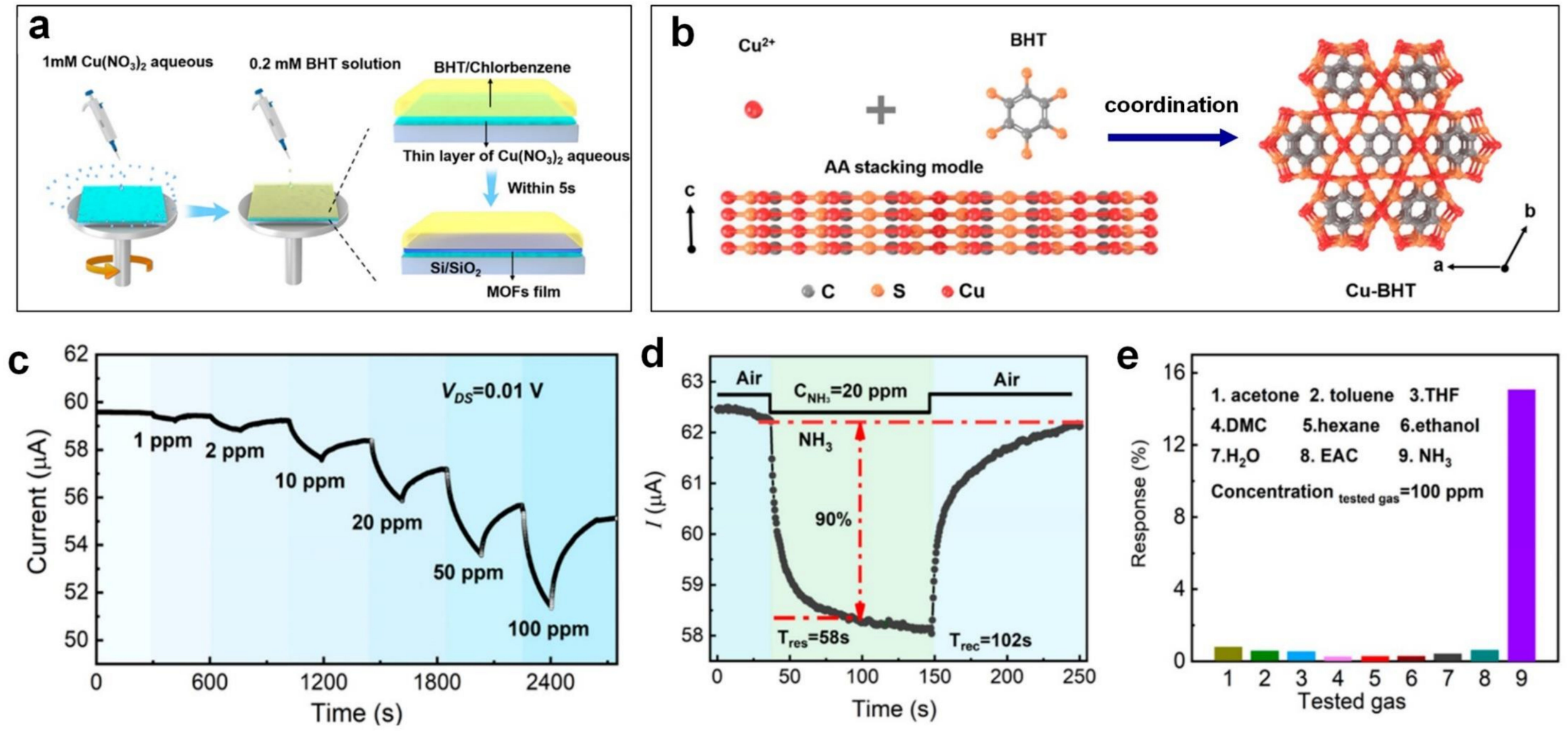

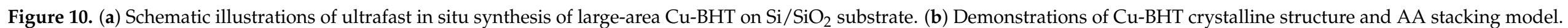

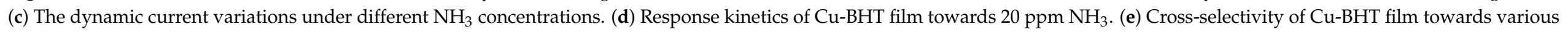
reducing gases with the concentration of 100 ppm. Reproduced with permission from [108] American Chemical Society, 2021. 
A 10-nm-thick Cu-BHT thin-film demonstrated an excellent sensing performance towards $\mathrm{NH}_{3}$ gas molecules (Figure 10c) with a sensing response of $\sim 16 \%$ upon exposure to $100 \mathrm{ppm} \mathrm{NH}_{3}$ and under a low driving voltage of $0.01 \mathrm{~V}$ (Figure 10e). This high sensitivity was 30-50 times higher compared to other gases including acetone, toluene and hexane, indicating strong selectivity towards the target gas (Figure 10e). In addition, a remarkable LOD of $0.23 \mathrm{ppm}$ and fast signal dynamic of $58 \mathrm{~s}$ and $102 \mathrm{~s}$ for response and recovery time, respectively, was recorded for $\mathrm{NH}_{3}$ gas with $20 \mathrm{ppm}$ concentration (Figure 10d). However, the gas sensing performance dropped from $7.88 \%$ to $4.01 \%$ by increasing the $\mathrm{RH}$ from 0 to $80 \%$, due to sensing site blockage by water vapour molecules. Thus, surface modifications, including integration of hydrophobic MOFs fillers (e.g., microporous MIL160/PDMS [161]) on the surface of Cu-BHT via Van der Waals interactions, are likely to significantly improve the sensing performance in a high humidity environment [162].

In another approach, a 2D conductive MOF-based sensor, namely, $\mathrm{Cu}_{3}(\mathrm{HITP})_{2}$, was synthesised by a drop-casting technique for sub-ppm detection of $\mathrm{NH}_{3}$ gas molecules under an applied bias of $0.1 \mathrm{~V}$ [109]. The fabricated sensor demonstrated a linear response with increasing concentration of $\mathrm{NH}_{3}$ gas from 0.5 to $10 \mathrm{ppm}$, indicating that $\mathrm{Cu}_{3}(\mathrm{HITP})_{2}$ is a promising candidate for the quantitative sensing of $\mathrm{NH}_{3}$ at a wide range of concentrations. Very recently, Khan et al. [111] reported the synthesis of Pd-Co@MOF-5 core-shell nanocomposite as a fast, highly sensitive, and selective gas sensor for sub-ppm detection of $\mathrm{NH}_{3}$ at room temperature. The nanocomposite sensor exhibited remarkable resistive signals upon exposure to ammonia gas molecules in the range of 1 to $90 \mathrm{ppm}$ concentration of $\mathrm{NH}_{3}$. The sensor's response increased linearly from 1.5 for $1 \mathrm{ppm}$ concentration to 80.17 for $90 \mathrm{ppm}$ concentration with a fast response dynamic of $46 \mathrm{~s}$ and $22 \mathrm{~s}$ for response and recovery time, respectively. This excellent sensing performance towards $\mathrm{NH}_{3}$ could be attributed to the rich open/unsaturated metal sites in the porous MOF- 5 structure and the surface carboxyl group providing extra absorption sites for ammonia interaction. In addition to high sensitivity, an excellent selectivity towards $\mathrm{NH}_{3}$ was reported with negligible response to other gases including ethanol, formaldehyde, acetone and benzene at the same gas concentration (90 ppm).

Most recently, a Cu-HHTP 3D thin film (20 nm in thickness) was prepared in a controllable layer-by-layer approach for $\mathrm{NH}_{3}$ gas sensing at room temperature [110]. Instead of using a flat substrate for $\mathrm{MOF}$ growth, a $\mathrm{TiO}_{2}$ nanowire array (NWAs) was grown on sapphire hydrothermally providing a large surface area, short charge and mass transport pathway. The fabricated films exhibited a response of 1.6 towards $100 \mathrm{ppm}$ $\mathrm{NH} 3$ gas with a fast response time of $35 \mathrm{~s}$. This was $600 \%$ and $130 \%$ faster compared to $\mathrm{Cu}-\mathrm{HHTP}$ powder and 2D thin film with the same thickness, respectively. A record low LOD of $\sim 87 \mathrm{ppt}$ and an excellent selectivity among the most common carbonaceous gases (such as $\mathrm{CO}_{2}, \mathrm{CO}, \mathrm{CH}_{4}, \mathrm{EtOH}, \mathrm{MeOH}$, acetone, etc.) and $\mathrm{H}_{2}$ was achieved. Such a high sensing performance at room temperature casts a bright light on $\mathrm{NH}_{3}$ gas sensing design. However, further work is encouraged to promote faster recovering kinetics as a $15 \mathrm{~min}$ recovery time impedes the potential of Cu-HHTP 3D thin film for practical applications.

\section{Summary and Outlook}

In summary, we have reviewed and discussed in detail recent advances in the development of MOF-based nanosensors for air quality and environmental monitoring applications. In this comprehensive review, the main focus has been on the most recent research progress in capacitive, optical and chemoresistive sensors made of MOF nanoparticles and nanofilms. The sensing performance, along with the corresponding sensing mechanisms of the state-ofthe-art technologies, was carefully investigated for the room temperature detection of gases including $\mathrm{NO}_{2}, \mathrm{SO}_{2}, \mathrm{H}_{2} \mathrm{~S}, \mathrm{CO}_{2}$ and $\mathrm{NH}_{3}$ with a wide variety of MOF-based nanosensing technologies.

High sensitivity and selectivity at low operating temperatures have been reported for state-of-the-art MOF-based sensors making them a promising candidate for various 
gas-sensing applications; however, MOF-based nanosensors for sub-ppb detection of gas molecules are still in the initial stages of development, with much room to improve the sensing performance of these MOF materials and many opportunities to enhance their LODs towards gas molecules.

High chemical, thermal, and photo stabilities have been achieved for some of the MOFbased sensing technologies, which determine their repeatability and long-term reusability. However, recent studies have indicated that some of the widely used MOFs for gas sensors undergo partial degradation upon exposure to moisture. Continued efforts are necessary for the design and development of robust MOF-based sensing materials to demonstrate long-term stability in different environments. Careful assessment of MOF sensors after longterm tests using analytical techniques sensitive to MOF degradation will enable researchers to improve their stability. The careful design of novel MOF structures (such as mixed metal ions, hydrophobic ligands, and interpenetration of frameworks), post-processing of current MOFs (such as metal/ligand exchange, hydrophobic surface modification, and thermal treatment), and compositing MOFs with, or encapsulating MOFs into, other materials (such as polymers, carbon nanotubes, graphenes and graphene oxide) are among the proposed techniques for improving the chemical stability of MOFs.

Among several different fabrication techniques, the solvothermal method is the most common synthesis method to produce MOF particles which are then incorporated into the sensing devices using drop coating, spin coating, electrospinning, etc. Despite the progress in nanofabrication methodologies, there have been limited investigations that consider environmentally friendly synthesis techniques to form MOFs for gas-sensing purposes using a green approach with high yield, hence minimum wastes [69,70]. Fabrication of MOFs through a green and scalable route is of great importance to their commercial translation and real-life application.

The inherently low electrical conductivity of most MOFs has severely limited their applications in gas and liquid sensors. However, the development of highly porous 2D conductive MOFs with tunable cavity size has facilitated the rise of MOF-based sensing technologies. In addition, the design of novel nanomaterials, including guest-MOF nanostructures where MOFs and guest molecules are combined, has shown excellent enhancement in the conductivity of MOF-based gas sensors.

The future is bright for the development of highly sensitive and selective MOF-based nanosensors for room temperature detection of low concentrations of gas molecules, with applications in many areas of technology, industry, or daily life, providing strong health, safety and security benefits to address many standing fundamental and technological challenges.

Funding: This research received no external funding.

Institutional Review Board Statement: Not applicable.

Informed Consent Statement: Not applicable.

Data Availability Statement: Not applicable.

Conflicts of Interest: The authors declare no conflict of interest.

\section{References}

1. Lustig, W.P.; Mukherjee, S.; Rudd, N.D.; Desai, A.V.; Li, J.; Ghosh, S.K. Metal-organic frameworks: Functional luminescent and photonic materials for sensing applications. Chem. Soc. Rev. 2017, 46, 3242-3285. [CrossRef]

2. Fang, X.; Zong, B.; Mao, S. Metal-Organic Framework-Based Sensors for Environmental Contaminant Sensing. Nano-Micro Lett. 2018, 10, 64. [CrossRef] [PubMed]

3. Zhou, X.; Xue, Z.; Chen, X.; Huang, C.; Bai, W.; Lu, Z.; Wang, T. Nanomaterial-based gas sensors used for breath diagnosis. J. Mater. Chem. B 2020, 8, 3231-3248. [CrossRef]

4. Nasiri, N.; Clarke, C. Nanostructured Gas Sensors for Medical and Health Applications: Low to High Dimensional Materials. Biosensors 2019, 9, 43. [CrossRef]

5. Nasiri, N.; Clarke, C. Nanostructured Chemiresistive Gas Sensors for Medical Applications. Sensors 2019, 19, 462. [CrossRef] [PubMed] 
6. Chen, X.; Leishman, M.; Bagnall, D.; Nasiri, N. Nanostructured Gas Sensors: From Air Quality and Environmental Monitoring to Healthcare and Medical Applications. Nanomaterials 2021, 11, 1927. [CrossRef]

7. Korotcenkov, G.; Cho, B.K. Metal oxide composites in conductometric gas sensors: Achievements and challenges. Sens. Actuators B Chem. 2017, 244, 182-210. [CrossRef]

8. Li, H.-Y.; Zhao, S.-N.; Zang, S.-Q.; Li, J. Functional metal-organic frameworks as effective sensors of gases and volatile compounds. Chem. Soc. Rev. 2020, 49, 6364-6401. [CrossRef] [PubMed]

9. Yuan, H.; Tao, J.; Li, N.; Karmakar, A.; Tang, C.; Cai, H.; Pennycook, S.J.; Singh, N.; Zhao, D. On-Chip Tailorability of Capacitive Gas Sensors Integrated with Metal-Organic Framework Films. Angew. Chem. 2019, 131, 14227-14232. [CrossRef]

10. Wang, H.; Lustig, W.P.; Li, J. Sensing and capture of toxic and hazardous gases and vapors by metal-organic frameworks. Chem. Soc. Rev. 2018, 47, 4729-4756. [CrossRef]

11. Rasheed, T.; Nabeel, F. Luminescent metal-organic frameworks as potential sensory materials for various environmental toxic agents. Coord. Chem. Rev. 2019, 401, 213065. [CrossRef]

12. Wenger, O.S. Vapochromism in Organometallic and Coordination Complexes: Chemical Sensors for Volatile Organic Compounds. Chem. Rev. 2013, 113, 3686-3733. [CrossRef]

13. Dolgopolova, E.A.; Rice, A.M.; Martin, C.R.; Shustova, N.B. Photochemistry and photophysics of MOFs: Steps towards MOFbased sensing enhancements. Chem. Soc. Rev. 2018, 47, 4710-4728. [CrossRef] [PubMed]

14. Yan, B. Lanthanide-Functionalized Metal-Organic Framework Hybrid Systems to Create Multiple Luminescent Centers for Chemical Sensing. Acc. Chem. Res. 2017, 50, 2789-2798. [CrossRef]

15. Wang, X.-D.; Wolfbeis, O.S. Optical methods for sensing and imaging oxygen: Materials, spectroscopies and applications. Chem. Soc. Rev. 2014, 43, 3666-3761. [CrossRef] [PubMed]

16. Dey, A. Semiconductor metal oxide gas sensors: A review. Mater. Sci. Eng. B Solid-State Mater. Adv. Technol. 2018, 229, 206-217. [CrossRef]

17. Hu, Z.; Deibert, B.J.; Li, J. Luminescent metal-organic frameworks for chemical sensing and explosive detection. Chem. Soc. Rev. 2014, 43, 5815-5840. [CrossRef]

18. Karmakar, A.; Samanta, P.; Desai, A.V.; Ghosh, S.K. Guest-Responsive Metal-Organic Frameworks as Scaffolds for Separation and Sensing Applications. Acc. Chem. Res. 2017, 50, 2457-2469. [CrossRef]

19. Stassen, I.; Burtch, N.; Talin, A.; Falcaro, P.; Allendorf, M.; Ameloot, R. An updated roadmap for the integration of metal-organic frameworks with electronic devices and chemical sensors. Chem. Soc. Rev. 2017, 46, 3185-3241. [CrossRef]

20. Wales, D.J.; Grand, J.; Ting, V.P.; Burke, R.D.; Edler, K.J.; Bowen, C.R.; Mintova, S.; Burrows, A.D. Gas sensing using porous materials for automotive applications. Chem. Soc. Rev. 2015, 44, 4290-4321. [CrossRef]

21. Kreno, L.E.; Leong, K.; Farha, O.K.; Allendorf, M.; Van Duyne, R.P.; Hupp, J.T. Metal-Organic Framework Materials as Chemical Sensors. Chem. Rev. 2012, 112, 1105-1125. [CrossRef]

22. Reglero Ruiz, J.; Sanjuán, A.; Vallejos, S.; García, F.; García, J. Smart Polymers in Micro and Nano Sensory Devices. Chemosensors 2018, 6, 12. [CrossRef]

23. Ciprian, R.; Baratto, C.; Giglia, A.; Koshmak, K.; Vinai, G.; Donarelli, M.; Ferroni, M.; Campanini, M.; Comini, E.; Ponzoni, A.; et al. Magnetic gas sensing exploiting the magneto-optical Kerr effect on ZnO nanorods/Co layer system. RSC Adv. 2016, 6, 42517-42521. [CrossRef]

24. Matatagui, D.; Kolokoltsev, O.V.; Qureshi, N.; Mejía-Uriarte, E.V.; Saniger, J.M. A magnonic gas sensor based on magnetic nanoparticles. Nanoscale 2015, 7, 9607-9613. [CrossRef] [PubMed]

25. Zou, C.W.; Wang, J.; Liang, F.; Xie, W.; Shao, L.X.; Fu, D.J. Large-area aligned CuO nanowires arrays: Synthesis, anomalous ferromagnetic and CO gas sensing properties. Curr. Appl. Phys. 2012, 12, 1349-1354. [CrossRef]

26. Impeng, S.; Junkaew, A.; Maitarad, P.; Kungwan, N.; Zhang, D.; Shi, L.; Namuangruk, S. A MnN 4 moiety embedded graphene as a magnetic gas sensor for CO detection: A first principle study. Appl. Surf. Sci. 2019, 473, 820-827. [CrossRef]

27. Zhu, C.; Gerald, R.E.; Huang, J. Metal-organic Framework Materials Coupled to Optical Fibers for Chemical Sensing: A Review. IEEE Sens. J. 2021, 1. [CrossRef]

28. Zhang, X.; Zhai, Z.; Wang, J.; Hao, X.; Sun, Y.; Yu, S.; Lin, X.; Qin, Y.; Li, C. Zr-MOF Combined with Nanofibers as an Efficient and Flexible Capacitive Sensor for Detecting $\mathrm{SO}_{2}$. ChemNanoMat 2021. [CrossRef]

29. Zhai, Z.; Zhang, X.; Hao, X.; Niu, B.; Li, C. Metal-Organic Frameworks Materials for Capacitive Gas Sensors. Adv. Mater. Technol. 2021, 2100127. [CrossRef]

30. Fernandez, E.; Saiz, P.G.; Peřinka, N.; Wuttke, S.; Fernández De Luis, R. Printed Capacitive Sensors Based on Ionic Liquid/MetalOrganic Framework Composites for Volatile Organic Compounds Detection. Adv. Funct. Mater. 2021, 31, 2010703. [CrossRef]

31. Srinivas, C.; Ranjith Kumar, E.; Tirupanyam, B.V.; Singh Meena, S.; Bhatt, P.; Prajapat, C.L.; Chandrasekhar Rao, T.V.; Sastry, D.L. Study of magnetic behavior in co-precipitated Ni-Zn ferrite nanoparticles and their potential use for gas sensor applications. J. Magn. Magn. Mater. 2020, 502, 166534. [CrossRef]

32. Sava Gallis, D.F.; Vogel, D.J.; Vincent, G.A.; Rimsza, J.M.; Nenoff, T.M. NO $\mathrm{x}_{\mathrm{x}}$ Adsorption and Optical Detection in Rare Earth Metal-Organic Frameworks. ACS Appl. Mater. Interfaces 2019, 11, 43270-43277. [CrossRef]

33. Chen, H.; Bo, R.; Shrestha, A.; Xin, B.; Nasiri, N.; Zhou, J.; Di Bernardo, I.; Dodd, A.; Saunders, M.; Lipton-Duffin, J.; et al. $\mathrm{NiO}-\mathrm{ZnO}$ Nanoheterojunction Networks for Room-Temperature Volatile Organic Compounds Sensing. Adv. Opt. Mater. 2018, 6, 1800677. [CrossRef] 
34. Gerber, A.; Kopnov, G.; Karpovski, M. Hall effect spintronics for gas detection. Appl. Phys. Lett. 2017, 111, 143505. [CrossRef]

35. Alam, M.F.B.; Phan, D.-T.; Chung, G.-S. Palladium nanocubes decorated on a one-dimensional ZnO nanorods array for use as a hydrogen gas sensor. Mater. Lett. 2015, 156, 113-117. [CrossRef]

36. Yang, S.; Lei, G.; Xu, H.; Lan, Z.; Wang, Z.; Gu, H. Metal Oxide Based Heterojunctions for Gas Sensors: A Review. Nanomaterials 2021, 11, 1026. [CrossRef]

37. Zhang, J.; Qin, Z.; Zeng, D.; Xie, C. Metal-oxide-semiconductor based gas sensors: Screening, preparation, and integration. Phys. Chem. Chem. Phys. 2017, 19, 6313-6329. [CrossRef] [PubMed]

38. Cichosz, S.; Masek, A.; Zaborski, M. Polymer-based sensors: A review. Polym. Test. 2018, 67, 342-348. [CrossRef]

39. Fratoddi, I.; Venditti, I.; Cametti, C.; Russo, M.V. Chemiresistive polyaniline-based gas sensors: A mini review. Sens. Actuators B Chem. 2015, 220, 534-548. [CrossRef]

40. Ding, B.; Yamazaki, M.; Shiratori, S. Electrospun fibrous polyacrylic acid membrane-based gas sensors. Sens. Actuators B Chem. 2005, 106, 477-483. [CrossRef]

41. Barauskas, D.; Pelenis, D.; Vanagas, G.; Viržonis, D.; Baltrušaitis, J. Methylated Poly(ethylene)imine Modified Capacitive Micromachined Ultrasonic Transducer for Measurements of $\mathrm{CO}_{2}$ and $\mathrm{SO}_{2}$ in Their Mixtures. Sensors 2019, 19, 3236. [CrossRef]

42. Gargiulo, V.; Alfano, B.; Di Capua, R.; Alfé, M.; Vorokhta, M.; Polichetti, T.; Massera, E.; Miglietta, M.L.; Schiattarella, C.; Di Francia, G. Graphene-like layers as promising chemiresistive sensing material for detection of alcohols at low concentration. J. Appl. Phys. 2018, 123, 024503. [CrossRef]

43. Li, C.; Wang, Y.; Jiang, H.; Wang, X. Review_Intracellular Sensors Based on Carbonaceous Nanomaterials: A Review. J. Electrochem. Soc. 2020, 167, 037540. [CrossRef]

44. Wang, Y.; Yeow, J.T.W. A Review of Carbon Nanotubes-Based Gas Sensors. J. Sens. 2009, 2009, 493904. [CrossRef]

45. Zhang, T.; Mubeen, S.; Myung, N.V.; Deshusses, M.A. Recent progress in carbon nanotube-based gas sensors. Nanotechnology 2008, 19, 332001. [CrossRef]

46. Llobet, E. Gas sensors using carbon nanomaterials: A review. Sens. Actuators B Chem. 2013, 179, 32-45. [CrossRef]

47. Lee, J.M.; Park, J.-E.; Kim, S.; Kim, S.; Lee, E.; Kim, S.-J.; Lee, W. Ultra-sensitive hydrogen gas sensors based on Pd-decorated tin dioxide nanostructures: Room temperature operating sensors. Int. J. Hydrog. Energy 2010, 35, 12568-12573. [CrossRef]

48. Sharma, B.; Kim, J.-S. Graphene decorated Pd-Ag nanoparticles for $\mathrm{H}_{2}$ sensing. Int. J. Hydrog. Energy 2018, 43, 11397-11402. [CrossRef]

49. Zhang, S.; Yang, M.; Liang, K.; Turak, A.; Zhang, B.; Meng, D.; Wang, C.; Qu, F.; Cheng, W.; Yang, M. An acetone gas sensor based on nanosized Pt-loaded $\mathrm{Fe}_{2} \mathrm{O}_{3}$ nanocubes. Sens. Actuators B Chem. 2019, 290, 59-67. [CrossRef]

50. Barbosa, M.S.; Suman, P.H.; Kim, J.J.; Tuller, H.L.; Orlandi, M.O. Investigation of electronic and chemical sensitization effects promoted by $\mathrm{Pt}$ and $\mathrm{Pd}$ nanoparticles on single-crystalline SnO nanobelt-based gas sensors. Sens. Actuators B Chem. 2019, 301, 127055. [CrossRef]

51. Gębicki, J.; Kloskowski, A.; Chrzanowski, W.; Stepnowski, P.; Namiesnik, J. Application of Ionic Liquids in Amperometric Gas Sensors. Crit. Rev. Anal. Chem. 2016, 46, 122-138. [CrossRef]

52. Paul, A.; Muthukumar, S.; Prasad, S. Room-temperature ionic liquids for electrochemical application with special focus on gas sensors. J. Electrochem. Soc. 2019, 167, 037511. [CrossRef]

53. Zevenbergen, M.A.G.; Wouters, D.; Dam, V.-A.T.; Brongersma, S.H.; Crego-Calama, M. Electrochemical Sensing of Ethylene Employing a Thin Ionic-Liquid Layer. Anal. Chem. 2011, 83, 6300-6307. [CrossRef] [PubMed]

54. Li, Y.; Xiao, A.-S.; Zou, B.; Zhang, H.-X.; Yan, K.-L.; Lin, Y. Advances of metal-organic frameworks for gas sensing. Polyhedron 2018, 154, 83-97. [CrossRef]

55. Kumar, P.; Deep, A.; Kim, K.-H. Metal organic frameworks for sensing applications. TrAC—Trends Anal. Chem. 2015, 73, 39-53. [CrossRef]

56. Hu, M.-L.; Razavi, S.A.A.; Piroozzadeh, M.; Morsali, A. Sensing organic analytes by metal-organic frameworks: A new way of considering the topic. Inorg. Chem. Front. 2020, 7, 1598-1632. [CrossRef]

57. Abideen, Z.U.; Kim, J.-H.; Lee, J.-H.; Kim, J.-Y.; Mirzaei, A.; Kim, H.W.; Kim, S.S. Electrospun Metal Oxide Composite Nanofibers Gas Sensors: A Review. J. Korean Ceram. Soc. 2017, 54, 366-379. [CrossRef]

58. Wang, C.; Wang, Y.; Yang, Z.; Hu, N. Review of recent progress on graphene-based composite gas sensors. Ceram. Int. 2021, 47, 16367-16384. [CrossRef]

59. Love, C.; Nazemi, H.; El-Masri, E.; Ambrose, K.; Freund, M.S.; Emadi, A. A Review on Advanced Sensing Materials for Agricultural Gas Sensors. Sensors 2021, 21, 3423. [CrossRef]

60. Mirzaei, A.; Leonardi, S.G.; Neri, G. Detection of hazardous volatile organic compounds (VOCs) by metal oxide nanostructuresbased gas sensors: A review. Ceram. Int. 2016, 42, 15119-15141. [CrossRef]

61. Wang, J.; Shen, H.; Xia, Y.; Komarneni, S. Light-activated room-temperature gas sensors based on metal oxide nanostructures: A review on recent advances. Ceram. Int. 2021, 47, 7353-7368. [CrossRef]

62. Amiri, V.; Roshan, H.; Mirzaei, A.; Neri, G.; Ayesh, A.I. Nanostructured Metal Oxide-Based Acetone Gas Sensors: A Review. Sensors 2020, 20, 3096. [CrossRef] [PubMed]

63. Wang, C.; Yin, L.; Zhang, L.; Xiang, D.; Gao, R. Metal Oxide Gas Sensors: Sensitivity and Influencing Factors. Sensors 2010, 10, 2088-2106. [CrossRef] 
64. Moseley, P.T. Progress in the development of semiconducting metal oxide gas sensors: A review. Meas. Sci. Technol. 2017, 28, 082001. [CrossRef]

65. Adhikari, B.; Majumdar, S. Polymers in sensor applications. Prog. Polym. Sci. 2004, 29, 699-766. [CrossRef]

66. Yaghi, O.M.; O'Keeffe, M.; Ockwig, N.W.; Chae, H.K.; Eddaoudi, M.; Kim, J. Reticular synthesis and the design of new materials. Nature 2003, 423, 705-714. [CrossRef]

67. Furukawa, H.; Cordova, K.E.; O’Keeffe, M.; Yaghi, O.M. The Chemistry and Applications of Metal-Organic Frameworks. Science 2013, 341, 1230444. [CrossRef] [PubMed]

68. Bo, R.; Taheri, M.; Liu, B.; Ricco, R.; Chen, H.; Amenitsch, H.; Fusco, Z.; Tsuzuki, T.; Yu, G.; Ameloot, R.; et al. Hierarchical Metal-Organic Framework Films with Controllable Meso/Macroporosity. Adv. Sci. 2020, 7, 2002368. [CrossRef]

69. Taheri, M.; Bernardo, I.D.; Lowe, A.; Nisbet, D.R.; Tsuzuki, T. Green Full Conversion of ZnO Nanopowders to Well-Dispersed Zeolitic Imidazolate Framework-8 (ZIF-8) Nanopowders via a Stoichiometric Mechanochemical Reaction for Fast Dye Adsorption. Cryst. Growth Des. 2020, 20, 2761-2773. [CrossRef]

70. Chen, D.; Zhao, J.; Zhang, P.; Dai, S. Mechanochemical synthesis of metal-organic frameworks. Polyhedron 2019, 162, 59-64. [CrossRef]

71. Schukraft, G.; Petit, C. Green Synthesis and Engineering Applications of Metal-Organic Frameworks. In Sustainable Nanoscale Engineering; Szekely, G., Livingston, A., Eds.; Elsevier: Amsterdam, The Netherlands, 2020; pp. 139-162.

72. Kumar, S.; Jain, S.; Nehra, M.; Dilbaghi, N.; Marrazza, G.; Kim, K.-H. Green synthesis of metal-organic frameworks: A state-of-the-art review of potential environmental and medical applications. Coord. Chem. Rev. 2020, 420, 213407. [CrossRef]

73. Zhao, Y.; Song, Z.; Li, X.; Sun, Q.; Cheng, N.; Lawes, S.; Sun, X. Metal organic frameworks for energy storage and conversion. Energy Storage Mater. 2016, 2, 35-62. [CrossRef]

74. Yang, J.; Yang, Y.W. Metal-Organic Frameworks for Biomedical Applications. Small 2020, 16, 1906846. [CrossRef] [PubMed]

75. Zhang, H.; Nai, J.; Yu, L.; Lou, X.W. Metal-Organic-Framework-Based Materials as Platforms for Renewable Energy and Environmental Applications. Joule 2017, 1, 77-107. [CrossRef]

76. Taheri, M.; Ashok, D.; Sen, T.; Enge, T.G.; Verma, N.K.; Tricoli, A.; Lowe, A.; Nisbet, D.R.; Tsuzuki, T. Stability of ZIF-8 nanopowders in bacterial culture media and its implication for antibacterial properties. Chem. Eng. J. 2021, 413, 127511. [CrossRef]

77. Liu, B.; Taheri, M.; Torres, J.F.; Fusco, Z.; Lu, T.; Liu, Y.; Tsuzuki, T.; Yu, G.; Tricoli, A. Janus Conductive/Insulating Microporous Ion-Sieving Membranes for Stable Li-S Batteries. ACS Nano 2020, 14, 13852-13864. [CrossRef]

78. Song, L.-F.; Jiang, C.-H.; Jiao, C.-L.; Zhang, J.; Sun, L.-X.; Xu, F.; You, W.-S.; Wang, Z.-G.; Zhao, J.-J. Two New Metal-Organic Frameworks with Mixed Ligands of Carboxylate and Bipyridine: Synthesis, Crystal Structure, and Sensing for Methanol. Cryst. Growth Des. 2010, 10, 5020-5023. [CrossRef]

79. Achmann, S.; Hagen, G.; Kita, J.; Malkowsky, I.; Kiener, C.; Moos, R. Metal-Organic Frameworks for Sensing Applications in the Gas Phase. Sensors 2009, 9, 1574-1589. [CrossRef]

80. Yao, M.-S.; Lv, X.-J.; Fu, Z.-H.; Li, W.-H.; Deng, W.-H.; Wu, G.-D.; Xu, G. Layer-by-Layer Assembled Conductive Metal-Organic Framework Nanofilms for Room-Temperature Chemiresistive Sensing. Angew. Chem. 2017, 129, 16737-16741. [CrossRef]

81. Arul, C.; Moulaee, K.; Donato, N.; Iannazzo, D.; Lavanya, N.; Neri, G.; Sekar, C. Temperature modulated Cu-MOF based gas sensor with dual selectivity to acetone and $\mathrm{NO}_{2}$ at low operating temperatures. Sens. Actuators B Chem. 2021, 329. [CrossRef]

82. Koo, W.T.; Jang, J.S.; Kim, I.D. Metal-Organic Frameworks for Chemiresistive Sensors. Chem 2019, 5, 1938-1963. [CrossRef]

83. Lai, C.; Wang, Z.; Qin, L.; Fu, Y.; Li, B.; Zhang, M.; Liu, S.; Li, L.; Yi, H.; Liu, X.; et al. Metal-organic frameworks as burgeoning materials for the capture and sensing of indoor VOCs and radon gases. Coord. Chem. Rev. 2021, 427, 213565. [CrossRef]

84. Gamonal, A.; Sun, C.; Mariano, A.L.; Fernandez-Bartolome, E.; Guerrero-Sanvicente, E.; Vlaisavljevich, B.; Castells-Gil, J.; Marti-Gastaldo, C.; Poloni, R.; Wannemacher, R.; et al. Divergent Adsorption-Dependent Luminescence of Amino-Functionalized Lanthanide Metal-Organic Frameworks for Highly Sensitive $\mathrm{NO}_{2}$ Sensors. J. Phys. Chem. Lett. 2020, 11, 3362-3368. [CrossRef] [PubMed]

85. Ma, Y.-X.; Gao, B.; Li, Y.; Wei, W.; Zhao, Y.; Ma, J.-F. Macrocycle-Based Metal-Organic Frameworks with $\mathrm{NO}_{2}$-Driven On/Off Switch of Conductivity. ACS Appl. Mater. Interfaces 2021, 13, 27066-27073. [CrossRef]

86. Small, L.J.; Henkelis, S.E.; Rademacher, D.X.; Schindelholz, M.E.; Krumhansl, J.L.; Vogel, D.J.; Nenoff, T.M. Near-Zero Power MOF-Based Sensors for $\mathrm{NO}_{2}$ Detection. Adv. Funct. Mater. 2020, 30, 2006598. [CrossRef]

87. Liu, Y.; Wang, R.; Zhang, T.; Liu, S.; Fei, T. Zeolitic imidazolate framework-8 (ZIF-8)-coated $\mathrm{In}_{2} \mathrm{O}_{3}$ nanofibers as an efficient sensing material for ppb-level $\mathrm{NO}_{2}$ detection. J. Colloid Interface Sci. 2019, 541, 249-257. [CrossRef]

88. Jo, Y.-M.; Lim, K.; Yoon, J.W.; Jo, Y.K.; Moon, Y.K.; Jang, H.W.; Lee, J.-H. Visible-Light-Activated Type II Heterojunction in $\mathrm{Cu}_{3}$ (hexahydroxytriphenylene $)_{2} / \mathrm{Fe}_{2} \mathrm{O}_{3}$ Hybrids for Reversible $\mathrm{NO}_{2}$ Sensing: Critical Role of $\pi-\pi^{*}$ Transition. ACS Cent. Sci. 2021, 7, 1176-1182. [CrossRef]

89. Koo, W.T.; Kim, S.J.; Jang, J.S.; Kim, D.H.; Kim, I.D. Catalytic Metal Nanoparticles Embedded in Conductive Metal-Organic Frameworks for Chemiresistors: Highly Active and Conductive Porous Materials. Adv. Sci. 2019, 6, 1900250. [CrossRef] [PubMed]

90. Kim, J.-O.; Koo, W.-T.; Kim, H.; Park, C.; Lee, T.; Hutomo, C.A.; Choi, S.Q.; Kim, D.S.; Kim, I.-D.; Park, S. Large-area synthesis of nanoscopic catalyst-decorated conductive MOF film using microfluidic-based solution shearing. Nat. Commun. 2021, 12. [CrossRef]

91. Zhan, M.; Hussain, S.; AlGarni, T.S.; Shah, S.; Liu, J.; Zhang, X.; Ahmad, A.; Javed, M.S.; Qiao, G.; Liu, G. Facet controlled polyhedral ZIF-8 MOF nanostructures for excellent $\mathrm{NO}_{2}$ gas-sensing applications. Mater. Res. Bull. 2021, 136, 111133. [CrossRef] 
92. Zhang, J.; Liu, F.; Gan, J.; Cui, Y.; Li, B.; Yang, Y.; Qian, G. Metal-organic framework film for fluorescence turn-on $\mathrm{H}_{2} \mathrm{~S}$ gas sensing and anti-counterfeiting patterns. Sci. China Mater. 2019, 62, 1445-1453. [CrossRef]

93. Yassine, O.; Shekhah, O.; Assen, A.H.; Belmabkhout, Y.; Salama, K.N.; Eddaoudi, M. $\mathrm{H}_{2} \mathrm{~S}$ Sensors: Fumarate-Based fcu-MOF Thin Film Grown on a Capacitive Interdigitated Electrode. Angew. Chem. 2016, 128, 16111-16115. [CrossRef]

94. Wu, X.; Xiong, S.; Gong, Y.; Gong, Y.; Wu, W.; Mao, Z.; Liu, Q.; Hu, S.; Long, X. MOF-SMO hybrids as a $\mathrm{H}_{2} \mathrm{~S}$ sensor with superior sensitivity and selectivity. Sens. Actuators B Chem. 2019, 292, 32-39. [CrossRef]

95. Ali, A.; Alzamly, A.; Greish, Y.E.; Bakiro, M.; Nguyen, H.L.; Mahmoud, S.T. A Highly Sensitive and Flexible Metal-Organic Framework Polymer-Based $\mathrm{H}_{2} \mathrm{~S}$ Gas Sensor. ACS Omega 2021, 6, 17690-17697. [CrossRef]

96. Smith, M.K.; Mirica, K.A. Self-Organized Frameworks on Textiles (SOFT): Conductive Fabrics for Simultaneous Sensing, Capture, and Filtration of Gases. J. Am. Chem. Soc. 2017, 139, 16759-16767. [CrossRef]

97. Meng, Z.; Aykanat, A.; Mirica, K.A. Welding Metallophthalocyanines into Bimetallic Molecular Meshes for Ultrasensitive, Low-Power Chemiresistive Detection of Gases. J. Am. Chem. Soc. 2019, 141, 2046-2053. [CrossRef]

98. Wang, M.; Guo, L.; Cao, D. Amino-Functionalized Luminescent Metal-Organic Framework Test Paper for Rapid and Selective Sensing of $\mathrm{SO}_{2}$ Gas and Its Derivatives by Luminescence Turn-On Effect. Anal. Chem. 2018, 90, 3608-3614. [CrossRef]

99. Zhang, J.; Xia, T.; Zhao, D.; Cui, Y.; Yang, Y.; Qian, G. In situ secondary growth of Eu(III)-organic framework film for fluorescence sensing of sulfur dioxide. Sens. Actuators B Chem. 2018, 260, 63-69. [CrossRef]

100. Chernikova, V.; Yassine, O.; Shekhah, O.; Eddaoudi, M.; Salama, K.N. Highly sensitive and selective $\mathrm{SO}_{2} \mathrm{MOF}$ sensor: The integration of MFM-300 MOF as a sensitive layer on a capacitive interdigitated electrode. J. Mater. Chem. A 2018, 6, 5550-5554. [CrossRef]

101. Dmello, M.E.; Sundaram, N.G.; Singh, A.; Singh, A.K.; Kalidindi, S.B. An amine functionalized zirconium metal-organic framework as an effective chemiresistive sensor for acidic gases. Chem. Commun. 2019, 55, 349-352. [CrossRef]

102. Ingle, N.; Sayyad, P.; Deshmukh, M.; Bodkhe, G.; Mahadik, M.; Al-Gahouari, T.; Shirsat, S.; Shirsat, M.D. A chemiresistive gas sensor for sensitive detection of $\mathrm{SO}_{2}$ employing Ni-MOF modified-OH-SWNTs and-OH-MWNTs. Appl. Phys. A 2021, 127. [CrossRef]

103. Kim, K.-J.; Lu, P.; Culp, J.T.; Ohodnicki, P.R. Metal-Organic Framework Thin Film Coated Optical Fiber Sensors: A Novel Waveguide-Based Chemical Sensing Platform. ACS Sens. 2018, 3, 386-394. [CrossRef]

104. Stassen, I.; Dou, J.-H.; Hendon, C.; Dincă, M. Chemiresistive Sensing of Ambient $\mathrm{CO}_{2}$ by an Autogenously Hydrated $\mathrm{Cu}_{3}$ (hexaiminobenzene) ${ }_{2}$ Framework. ACS Cent. Sci. 2019, 5, 1425-1431. [CrossRef]

105. Dmello, M.E.; Sundaram, N.G.; Kalidindi, S.B. Assembly of ZIF-67 Metal-Organic Framework over Tin Oxide Nanoparticles for Synergistic Chemiresistive $\mathrm{CO}_{2}$ Gas Sensing. Chem. Eur. J. 2018, 24, 9220-9223. [CrossRef] [PubMed]

106. Zhang, J.; Yue, D.; Xia, T.; Cui, Y.; Yang, Y.; Qian, G. A luminescent metal-organic framework film fabricated on porous $\mathrm{Al}_{2} \mathrm{O}_{3}$ substrate for sensitive detecting ammonia. Microporous Mesoporous Mater. 2017, 253, 146-150. [CrossRef]

107. Assen, A.H.; Yassine, O.; Shekhah, O.; Eddaoudi, M.; Salama, K.N. MOFs for the Sensitive Detection of Ammonia: Deployment of fcu-MOF Thin Films as Effective Chemical Capacitive Sensors. ACS Sens. 2017, 2, 1294-1301. [CrossRef] [PubMed]

108. Chen, X.; Lu, Y.; Dong, J.; Ma, L.; Yi, Z.; Wang, Y.; Wang, L.; Wang, S.; Zhao, Y.; Huang, J.; et al. Ultrafast In Situ Synthesis of Large-Area Conductive Metal-Organic Frameworks on Substrates for Flexible Chemiresistive Sensing. ACS Appl. Mater. Interfaces 2020, 12, 57235-57244. [CrossRef]

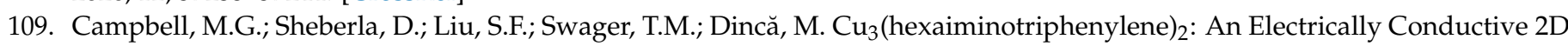
Metal-Organic Framework for Chemiresistive Sensing. Angew. Chem. Int. Ed. 2015, 54, 4349-4352. [CrossRef] [PubMed]

110. Lin, Y.; Li, W.-H.; Wen, Y.; Wang, G.-E.; Ye, X.; Xu, G. Layer-by-layer Growth of Preferred-Oriented MOF Thin Film on Nanowire Array for High-Performance Chemiresistive Sensing. Angew. Chem. Int. Ed. 2021. [CrossRef]

111. Khan, F.U.; Mehmood, S.; Zhao, X.; Yang, Y.; Pan, X. Ultra-Sensitive Bimetallic Alloy Loaded with Porous Architecture MOF for Ammonia Detection at Room Temperature. In Proceedings of the 2021 IEEE International Symposium on Circuits and Systems (ISCAS), Daegu, Korea, 22-28 May 2021.

112. Reddy, A.J.M.; Katari, N.K.; Nagaraju, P.; Surya, S.M. ZIF-8, Zn(NA) and Zn(INA) MOFs as chemical selective sensors of ammonia, formaldehyde and ethanol gases. Mater. Chem. Phys. 2020, 241, 122357. [CrossRef]

113. Li, Y.-P.; Li, S.-N.; Jiang, Y.-C.; Hu, M.-C.; Zhai, Q.-G. A semiconductor and fluorescence dual-mode room-temperature ammonia sensor achieved by decorating hydroquinone into a metal-organic framework. Chem. Commun. 2018, 54, 9789-9792. [CrossRef] [PubMed]

114. Travlou, N.A.; Singh, K.; Rodríguez-Castellón, E.; Bandosz, T.J. Cu-BTC MOF-graphene-based hybrid materials as low concentration ammonia sensors. J. Mater. Chem. A 2015, 3, 11417-11429. [CrossRef]

115. Gaba, A.; Felicia, S. Reduction of Air Pollution by Combustion Processes. In The Impact of Air Pollution on Health, Economy, Environment and Agricultural Sources; InTech: London, UK, 2011; pp. 119-142.

116. WHO. Air Quality Guidelines for Particulate Matter, Ozone, Nitrogen Dioxide and Sulfur Dioxide: Global Update 2005; WHO: Geneva, Switzerland, 2006.

117. Chen, T.-M.; Kuschner, W.G.; Gokhale, J.; Shofer, S. Outdoor Air Pollution: Nitrogen Dioxide, Sulfur Dioxide, and Carbon Monoxide Health Effects. Am. J. Med. Sci. 2007, 333, 249-256. [CrossRef]

118. Zhang, J.; Hu, E.; Liu, F.; Li, H.; Xia, T. Growth of robust metal-organic framework films by spontaneous oxidation of a metal substrate for $\mathrm{NO}_{2}$ sensing. Mater. Chem. Front. 2021. [CrossRef] 
119. Moscoso, F.G.; Almeida, J.; Sousaraei, A.; Lopes-Costa, T.; Silva, A.M.G.; Cabanillas-Gonzalez, J.; Cunha-Silva, L.; Pedrosa, J.M. Luminescent MOF crystals embedded in PMMA/PDMS transparent films as effective $\mathrm{NO}_{2}$ gas sensors. Mol. Syst. Des. Eng. 2020, 5, 1048-1056. [CrossRef]

120. Liu, C.; Kuang, Q.; Xie, Z.; Zheng, L. The effect of noble metal (Au, Pd and Pt) nanoparticles on the gas sensing performance of $\mathrm{SnO}_{2}$-based sensors: A case study on the $\{221\}$ high-index faceted $\mathrm{SnO}_{2}$ octahedra. CrystEngComm 2015, 17, 6308-6313. [CrossRef]

121. Kolmakov, A.; Klenov, D.O.; Lilach, Y.; Stemmer, S.; Moskovits, M. Enhanced Gas Sensing by Individual $\mathrm{SnO}_{2} \mathrm{Nanowires}$ and Nanobelts Functionalized with Pd Catalyst Particles. Nano Lett. 2005, 5, 667-673. [CrossRef]

122. Majhi, S.M.; Naik, G.K.; Lee, H.-J.; Song, H.-G.; Lee, C.-R.; Lee, I.-H.; Yu, Y.-T. Au@NiO core-shell nanoparticles as a p-type gas sensor: Novel synthesis, characterization, and their gas sensing properties with sensing mechanism. Sens. Actuators B Chem. 2018, 268, 223-231. [CrossRef]

123. Lee, J.-C.; Kim, J.-O.; Lee, H.-J.; Shin, B.; Park, S. Meniscus-Guided Control of Supersaturation for the Crystallization of High Quality Metal Organic Framework Thin Films. Chem. Mater. 2019, 31, 7377-7385. [CrossRef]

124. Meng, C.; Cui, X.; Qi, S.; Zhang, J.; Kang, J.; Zhou, H. Lung inflation with hydrogen sulfide during the warm ischemia phase ameliorates injury in rat donor lungs via metabolic inhibition after cardiac death. Surgery 2017, 161, 1287-1298. [CrossRef]

125. Zhou, X.; Lin, X.; Yang, S.; Zhu, S.; Chen, X.; Dong, B.; Bai, X.; Wen, X.; Geyu, L.; Song, H. Highly dispersed Metal-OrganicFramework-Derived $\mathrm{Pt}$ nanoparticles on three-dimensional macroporous $\mathrm{ZnO}$ for trace-level $\mathrm{H}_{2} \mathrm{~S}$ sensing. Sens. Actuators B Chem. 2020, 309, 127802. [CrossRef]

126. Ding, M.; Cai, X.; Jiang, H.-L. Improving MOF stability: Approaches and applications. Chem. Sci. 2019, 10, 10209-10230. [CrossRef]

127. U.S. Environmental Protection Agency. Primary National Ambient Air Quality Standard for Sulfur Dioxide; Final Rule. Fed. Regist. 2010, 75, 35520-35603.

128. Zhou, Q.; Zeng, W.; Chen, W.; Xu, L.; Kumar, R.; Umar, A. High sensitive and low-concentration sulfur dioxide $\left(\mathrm{SO}_{2}\right)$ gas sensor application of heterostructure NiO-ZnO nanodisks. Sens. Actuators B Chem. 2019, 298, 126870. [CrossRef]

129. Liu, L.; Liu, S. Oxygen Vacancies as an Efficient Strategy for Promotion of Low Concentration $\mathrm{SO}_{2}$ Gas Sensing: The Case of Au-Modified $\mathrm{SnO}_{2}$. ACS Sustain. Chem. Eng. 2018, 6, 13427-13434. [CrossRef]

130. Wang, X.; Yao, F.; Xu, P.; Li, M.; Yu, H.; Li, X. Quantitative Structure-Activity Relationship of Nanowire Adsorption to $\mathrm{SO}_{2}$ Revealed by In Situ TEM Technique. Nano Lett. 2021, 21, 1679-1687. [CrossRef] [PubMed]

131. Chaudhary, V.; Singh, H.; Kaur, A. Effect of charge carrier transport on sulfur dioxide monitoring performance of highly porous polyaniline nanofibres. Polym. Int. 2017, 66, 699-704. [CrossRef]

132. Zhao, C.H.; Gong, H.M.; Niu, G.Q.; Wang, F. Ultrasensitive $\mathrm{SO}_{2}$ sensor for sub-ppm detection using $\mathrm{Cu}_{\text {-doped }} \mathrm{SnO} \mathrm{O}_{2}$ nanosheet arrays directly grown on chip. Sens. Actuators B Chem. 2020, 324. [CrossRef]

133. Li, Q.; Wu, J.; Huang, L.; Gao, J.; Zhou, H.; Shi, Y.; Pan, Q.; Zhang, G.; Du, Y.; Liang, W. Sulfur dioxide gas-sensitive materials based on zeolitic imidazolate framework-derived carbon nanotubes. J. Mater. Chem. A 2018, 6, 12115-12124. [CrossRef]

134. Zhang, D.; Wu, D.; Zong, X.; Yang, Z. Enhanced $\mathrm{SO}_{2}$ gas sensing properties of metal organic frameworks-derived titanium dioxide/reduced graphene oxide nanostructure. J. Mater. Sci. Mater. Electron. 2019, 30, 11070-11078. [CrossRef]

135. Su, P.-G.; Zheng, Y.-L. Room-temperature ppb-level $\mathrm{SO}_{2}$ gas sensors based on $\mathrm{RGO} / \mathrm{WO}_{3}$ and $\mathrm{MWCNTs} / \mathrm{WO}_{3}$ nanocomposites. Anal. Methods 2021, 13, 782-788. [CrossRef] [PubMed]

136. Hoang, N.D.; Van Cat, V.; Nam, M.H.; Phan, V.N.; Le, A.T.; Van Quy, N. Enhanced $\mathrm{SO}_{2}$ sensing characteristics of multi-wall carbon nanotubes based mass-type sensor using two-step purification process. Sens. Actuators A Phys. 2019, 295, 696-702. [CrossRef]

137. Tan, K.; Zuluaga, S.; Wang, H.; Canepa, P.; Soliman, K.; Cure, J.; Li, J.; Thonhauser, T.; Chabal, Y.J. Interaction of Acid Gases SO 2 and $\mathrm{NO}_{2}$ with Coordinatively Unsaturated Metal Organic Frameworks: M-MOF-74 (M = Zn, Mg, Ni, Co). Chem. Mater. 2017, 29, 4227-4235. [CrossRef]

138. Hungerford, J.; Bhattacharyya, S.; Tumuluri, U.; Nair, S.; Wu, Z.; Walton, K.S. DMOF-1 as a Representative $\mathrm{MOF}$ for $\mathrm{SO}_{2}$ Adsorption in Both Humid and Dry Conditions. J. Phys. Chem. C 2018, 122, 23493-23500. [CrossRef]

139. Savage, M.; Cheng, Y.; Easun, T.L.; Eyley, J.E.; Argent, S.P.; Warren, M.R.; Lewis, W.; Murray, C.; Tang, C.C.; Frogley, M.D.; et al. Selective Adsorption of Sulfur Dioxide in a Robust Metal-Organic Framework Material. Adv. Mater. 2016, 28, 8705-8711. [CrossRef] [PubMed]

140. Brandt, P.; Xing, S.-H.; Liang, J.; Kurt, G.; Nuhnen, A.; Weingart, O.; Janiak, C. Zirconium and Aluminum MOFs for Low-Pressure $\mathrm{SO}_{2}$ Adsorption and Potential Separation: Elucidating the Effect of Small Pores and $\mathrm{NH}_{2}$ Groups. ACS Appl. Mater. Interfaces 2021, 13, 29137-29149. [CrossRef] [PubMed]

141. Sapsanis, C.; Omran, H.; Chernikova, V.; Shekhah, O.; Belmabkhout, Y.; Buttner, U.; Eddaoudi, M.; Salama, K. Insights on Capacitive Interdigitated Electrodes Coated with MOF Thin Films: Humidity and VOCs Sensing as a Case Study. Sensors 2015, 15, 18153-18166. [CrossRef]

142. Seesaard, T.; Kerdcharoen, T.; Wongchoosuk, C. Hybrid materials with carbon nanotubes for gas sensing. In Semiconductor Gas Sensors, 2nd ed.; Jaaniso, R., Tan, O.K., Eds.; Woodhead Publishing: Sawston, UK, 2020; pp. 185-222.

143. Ma, P.-C.; Liu, M.-Y.; Zhang, H.; Wang, S.-Q.; Wang, R.; Wang, K.; Wong, Y.-K.; Tang, B.-Z.; Hong, S.-H.; Paik, K.-W.; et al. Enhanced Electrical Conductivity of Nanocomposites Containing Hybrid Fillers of Carbon Nanotubes and Carbon Black. ACS Appl. Mater. Interfaces 2009, 1, 1090-1096. [CrossRef] 
144. Ingle, N.; Mane, S.; Sayyad, P.; Bodkhe, G.; Al-Gahouari, T.; Mahadik, M.; Shirsat, S.; Shirsat, M.D. Sulfur Dioxide (SO 2 ) Detection Using Composite of Nickel Benzene Carboxylic $\left(\mathrm{Ni}_{3} \mathrm{BTC}_{2}\right)$ and $\mathrm{OH}$-Functionalized Single Walled Carbon Nanotubes (OH-SWNTs). Front. Mater. Sci. 2020, 7, 93. [CrossRef]

145. Mao, S.; Lu, G.; Chen, J. Nanocarbon-based gas sensors: Progress and challenges. J. Mater. Chem. A 2014, 2, 5573. [CrossRef]

146. Boucher, O.; Friedlingstein, P.; Collins, B.; Shine, K.P. The indirect global warming potential and global temperature change potential due to methane oxidation. Environ. Res. Lett. 2009, 4, 044007. [CrossRef]

147. Hou, H.; Peng, S.; Xu, J.; Yang, S.; Mao, Z. Seasonal variations of $\mathrm{CH}_{4}$ and $\mathrm{N}_{2} \mathrm{O}$ emissions in response to water management of paddy fields located in Southeast China. Chemosphere 2012, 89, 884-892. [CrossRef] [PubMed]

148. Ritchie, H.; Roser, M. $\mathrm{CO}_{2}$ and Greenhouse Gas Emission. Available online: https://ourworldindata.org/co2-and-othergreenhouse-gas-emissions (accessed on 22 August 2021).

149. Ramalho, O.; Wyart, G.; Mandin, C.; Blondeau, P.; Cabanes, P.-A.; Leclerc, N.; Mullot, J.-U.; Boulanger, G.; Redaelli, M. Association of carbon dioxide with indoor air pollutants and exceedance of health guideline values. Build Environ. 2015, 93, 115-124. [CrossRef]

150. Jacobson, T.A.; Kler, J.S.; Hernke, M.T.; Braun, R.K.; Meyer, K.C.; Funk, W.E. Direct human health risks of increased atmospheric carbon dioxide. Nat. Sustain. 2019, 2, 691-701. [CrossRef]

151. Talin, A.A.; Centrone, A.; Ford, A.C.; Foster, M.E.; Stavila, V.; Haney, P.; Kinney, R.A.; Szalai, V.; El Gabaly, F.; Yoon, H.P.; et al. Tunable Electrical Conductivity in Metal-Organic Framework Thin-Film Devices. Science 2014, 343, 66-69. [CrossRef]

152. Strauss, I.; Mundstock, A.; Treger, M.; Lange, K.; Hwang, S.; Chmelik, C.; Rusch, P.; Bigall, N.C.; Pichler, T.; Shiozawa, H.; et al. Metal-Organic Framework Co-MOF-74-Based Host-Guest Composites for Resistive Gas Sensing. ACS Appl. Mater. Interfaces 2019, 11, 14175-14181. [CrossRef] [PubMed]

153. García, E.J.; Mowat, J.P.S.; Wright, P.A.; Pérez-Pellitero, J.; Jallut, C.; Pirngruber, G.D. Role of Structure and Chemistry in Controlling Separations of $\mathrm{CO}_{2} / \mathrm{CH}_{4}$ and $\mathrm{CO}_{2} / \mathrm{CH}_{4} / \mathrm{CO}$ Mixtures over Honeycomb MOFs with Coordinatively Unsaturated Metal Sites. J. Phys. Chem. C 2012, 116, 26636-26648. [CrossRef]

154. Chen, Z.; Deng, S.; Wei, H.; Wang, B.; Huang, J.; Yu, G. Activated carbons and amine-modified materials for carbon dioxide capture-A review. Front. Environ. Sci. Eng. 2013, 7, 326-340. [CrossRef]

155. Davey, A.K.; Gao, X.; Xia, Y.; Li, Z.; Dods, M.N.; Delacruz, S.; Pan, A.; Swamy, S.; Gardner, D.; Carraro, C.; et al. Aminefunctionalized metal-organic framework ZIF-8 toward colorimetric $\mathrm{CO}_{2}$ sensing in indoor air environment. Sens. Actuators $B$ Chem. 2021, 344, 130313. [CrossRef]

156. Yoon, B.; Choi, S.-J.; Swager, T.M.; Walsh, G.F. Switchable Single-Walled Carbon Nanotube-Polymer Composites for $\mathrm{CO}_{2}$ Sensing. ACS Appl. Mater. Interfaces 2018, 10, 33373-33379. [CrossRef]

157. Srinives, S.; Sarkar, T.; Hernandez, R.; Mulchandani, A. A miniature chemiresistor sensor for carbon dioxide. Anal. Chim. Acta 2015, 874, 54-58. [CrossRef]

158. Liu, G.K.; Zhu, L.J.; Yu, Y.M.; Qiu, M.; Gao, H.J.; Chen, D.Y. $\mathrm{WO}_{3}$ nanoplates for sensitive and selective detections of both acetone and $\mathrm{NH}_{3}$ gases at different operating temperatures. J. Alloys Compd. 2021, 858. [CrossRef]

159. Saidi, T.; Zaim, O.; Moufid, M.; El Bari, N.; Ionescu, R.; Bouchikhi, B. Exhaled breath analysis using electronic nose and gas chromatography-mass spectrometry for non-invasive diagnosis of chronic kidney disease, diabetes mellitus and healthy subjects. Sens. Actuators B Chem. 2018, 257, 178-188. [CrossRef]

160. Mitrayana, M.; Ma'arif, M.A.; Wasono, M.A.J.; Satriawan, M.; Ikhsan, M.R. Application of the $\mathrm{CO}_{2}$ laser photoacoustic spectroscopy in detecting ammonia gas $\left(\mathrm{NH}_{3}\right)$ in liver disease patients breath. Key Eng. Mater. 2020, 840, 399-405. [CrossRef]

161. Hwang, K.; Ahn, J.; Cho, I.; Kang, K.; Kim, K.; Choi, J.; Polychronopoulou, K.; Park, I. Microporous Elastomer Filter Coated with Metal Organic Frameworks for Improved Selectivity and Stability of Metal Oxide Gas Sensors. ACS Appl. Mater. Interfaces 2020, 12, 13338-13347. [CrossRef] [PubMed]

162. Yao, M.S.; Xiu, J.W.; Huang, Q.Q.; Li, W.H.; Wu, W.W.; Wu, A.Q.; Cao, L.A.; Deng, W.H.; Wang, G.E.; Xu, G. Van der Waals Heterostructured MOF-on-MOF Thin Films: Cascading Functionality to Realize Advanced Chemiresistive Sensing. Angew. Chem. 2019, 131, 15057-15061. [CrossRef] 